\title{
Aerosol indirect effects on the nighttime Arctic Ocean surface from thin, predominantly liquid clouds
}

\author{
Lauren M. Zamora ${ }^{1,2, *}$, Ralph A. Kahn², Sabine Eckhardt ${ }^{3}$, Allison McComiskey ${ }^{4}$, Patricia Sawamura ${ }^{5,6}$, \\ Richard Moore ${ }^{6}$, and Andreas Stohl ${ }^{3}$ \\ ${ }^{1}$ Earth System Science Interdisciplinary Center (ESSIC), University of Maryland, College Park, MD, USA \\ ${ }^{2}$ NASA Goddard Space Flight Center, Greenbelt, MD, USA \\ ${ }^{3}$ NILU - Norwegian Institute for Air Research, Kjeller, Norway \\ ${ }^{4}$ NOAA Earth System Research Laboratory, Boulder, CO, USA \\ ${ }^{5}$ Science Systems and Applications, Inc., Greenbelt, MD, USA \\ ${ }^{6}$ NASA Langley Research Center, Hampton, VA, USA \\ * former NASA Postdoctoral Program Fellow, Universities Space Research Association
}

Correspondence to: Lauren M. Zamora (lauren.m.zamora@nasa.gov)

Received: 21 November 2016 - Discussion started: 14 December 2016

Revised: 13 April 2017 - Accepted: 8 May 2017 - Published: 20 June 2017

\begin{abstract}
Aerosol indirect effects have potentially large impacts on the Arctic Ocean surface energy budget, but model estimates of regional-scale aerosol indirect effects are highly uncertain and poorly validated by observations. Here we demonstrate a new way to quantitatively estimate aerosol indirect effects on a regional scale from remote sensing observations. In this study, we focus on nighttime, optically thin, predominantly liquid clouds. The method is based on differences in cloud physical and microphysical characteristics in carefully selected clean, average, and aerosol-impacted conditions. The cloud subset of focus covers just $\sim 5 \%$ of cloudy Arctic Ocean regions, warming the Arctic Ocean surface by $\sim 1-1.4 \mathrm{~W} \mathrm{~m}^{-2}$ regionally during polar night. However, within this cloud subset, aerosol and cloud conditions can be determined with high confidence using CALIPSO and CloudSat data and model output. This cloud subset is generally susceptible to aerosols, with a polar nighttime estimated maximum regionally integrated indirect cooling effect of $\sim-0.11 \mathrm{~W} \mathrm{~m}^{-2}$ at the Arctic sea ice surface $(\sim 8 \%$ of the clean background cloud effect), excluding cloud fraction changes. Aerosol presence is related to reduced precipitation, cloud thickness, and radar reflectivity, and in some cases, an increased likelihood of cloud presence in the liquid phase. These observations are inconsistent with a glaciation indirect effect and are consistent with either a deactivation effect or less-efficient secondary ice formation related to smaller liq-
\end{abstract}

uid cloud droplets. However, this cloud subset shows large differences in surface and meteorological forcing in shallow and higher-altitude clouds and between sea ice and openocean regions. For example, optically thin, predominantly liquid clouds are much more likely to overlay another cloud over the open ocean, which may reduce aerosol indirect effects on the surface. Also, shallow clouds over open ocean do not appear to respond to aerosols as strongly as clouds over stratified sea ice environments, indicating a larger influence of meteorological forcing over aerosol microphysics in these types of clouds over the rapidly changing Arctic Ocean.

\section{Introduction}

Aerosol indirect effects on clouds are among the biggest uncertainties in climate models (Boucher et al., 2013). It is particularly important to reduce these uncertainties in the Arctic, where warming is occurring at a faster rate than in other locations (Serreze et al., 2009), and where local aerosol indirect effects can be large (Garrett et al., 2004; Garrett and Zhao, 2006; Lubin and Vogelmann, 2006; Zhao and Garrett, 2015). Understanding aerosol indirect effects is also important because aerosol emissions within and in the vicinity of the Arctic are changing, and perhaps more importantly, the 
major aerosol removal processes and transport pathways to the Arctic may be changing as well (Jiao and Flanner, 2016).

Unfortunately, accurate observation-based estimates of regional mean forcings are very difficult to obtain at most locations around the planet due to a variety of confounding factors and errors. These include (1) a reliance on proxies for cloud condensation nuclei $(\mathrm{CCN})$ and ice-nucleating particles (INPs); (2) meteorological co-variability and other synoptic-scale surface and atmospheric factors, including the aerosol spatial distribution; (3) the complexity of cloud responses to aerosol type and amount (Fan et al., 2016); (4) spatial and temporal limitations of the datasets; and (5) an insufficient understanding of cloud characteristics even in the absence of anthropogenic aerosols (Ghan et al., 2016; Wilcox et al., 2015). Knowledge of this last factor is difficult to obtain because pristine conditions are rare at most locations globally (Hamilton et al., 2014). To quantify mean regional aerosol indirect effects using observations, one would need datasets that cover the large spatial and temporal scales required to include the full range of natural heterogeneity, plus a way to correctly identify clean background conditions. As a result, current estimates of regional indirect aerosol impacts on the surface radiation rely predominantly upon models that still cannot accurately represent many relevant Arctic processes (e.g., Morrison et al., 2012; Ovchinnikov et al., 2014).

In some ways, isolating aerosol indirect effects over the Arctic Ocean can be even more challenging than in other regions. Sampling conditions at the ground are harsh, there is low thermal and visible contrast between sea ice and clouds, and observations are limited by the frequent presence of multilayer clouds. The very cold temperatures that characterize the Arctic affect chemical reactions and physical processes (e.g., the development of frost flowers, diamond dust, and blowing snow), making comparisons with lower-latitude systems more challenging. However, the Arctic Ocean is ideal for the study of indirect effects in other ways. For example, the surface and meteorological conditions over sea ice are highly homogenous compared to many other regions of the world. Moreover, pristine conditions still occur in this region with relatively high frequency, despite periodic episodes of combustion-derived aerosol transport from lower latitudes. Present-day observations in clean background conditions are among our best proxies for preindustrial conditions (Hamilton et al., 2014), and a better understanding of preindustrial conditions is, in turn, key to the ability to determine presentday indirect aerosol impacts on a regional scale (e.g., Gettleman, 2015; Ghan et al., 2016; Ghan, 2013; Carslaw et al., 2013; Wilcox et al., 2015; Kiehl et al., 2000).

Here we present a method for identifying spatially distributed properties in a subtype of Arctic Ocean clean background clouds using a combination of the CALIPSO and CloudSat active remote sensing instruments and an atmospheric transport model. We use the difference between average cloud characteristics gathered across the Arctic Ocean and average clean background clouds over the same region to estimate the maximum regional indirect aerosol impacts on the surface. This calculation provides an estimate of the actual regional impact of aerosol indirect effects on the surface, including aerosol and meteorological co-variability after stochastic meteorological effects have been taken into account. We also examine differences between the cloud characteristics under various aerosol conditions to assess cloud formation mechanisms in the presence of aerosol.

One goal of this work is to illustrate one way that regionalscale aerosol indirect effects on the surface can be obtained quantitatively from observational data. In the past, such estimates have primarily been supplied only by models. We focus on the subset of Arctic Ocean clouds where aerosol impacts can be identified with the greatest certainty: optically thin (cloud optical depth, $\mathrm{COD}<3$ ), predominantly liquid clouds during polar night. Optically thin, liquid-containing clouds are generally common over this region (Bennartz et al., 2013; Shupe and Intrieri, 2004). Such clouds are also effective at radiating longwave (LW) radiation downward (e.g., Garrett and Zhao, 2006), thus having a potentially large contribution to surface forcing (Shupe and Intrieri, 2004). Moreover, models tend to underpredict the formation of these optically thin clouds at supercooled temperatures (Cesana et al., 2012), making aerosol influences on droplet characteristics and ice nucleation of particular interest. Within the larger liquid-containing cloud group, this study focuses on predominantly liquid clouds, where aerosol conditions can be assessed with the highest certainty. The analysis is also limited to nighttime samples both to improve CALIPSO aerosolcondition assessments and to reduce confounding impacts from direct and semi-direct effects.

\section{Methods}

\subsection{Sample selection}

To describe aerosol impacts on Arctic Ocean clouds with high confidence using CALIPSO and CloudSat data, it was vital that we be able to accurately identify clean background cases. We selected a specific group of clouds where non-background aerosol (hereafter simply referred to as "aerosol") conditions and cloud properties could be ascertained with the greatest confidence. The main Arctic Ocean cloud subset of focus consists of clouds that are optically thin $(\mathrm{COD}<\sim 3)$, were collected at nighttime, and are predominantly liquid clouds, henceforth referred to as "ONLi" clouds for brevity. Because the ONLi cloud profiles were taken only at night, the majority of them were collected during the winter when there are relatively high aerosol inputs from lower latitudes (Shaw, 1995). Within the full ONLi cloud group, we identified subsets of clouds present in clean background and aerosol-influenced conditions. Results were also compared with an internal subset of clouds where aerosol conditions and cloud properties could be ascertained with even higher 
confidence (i.e., those clouds that were measured $>1 \mathrm{~km}$ above the surface, are optically thin $(\mathrm{COD}<\sim 3)$, were collected at nighttime, are predominantly liquid, and are from the top layer, henceforth referred to as "MOONLiT" clouds). The criteria for the cloud groups and aerosol classifications are summarized in Table 1. Justification for these criteria and descriptions of the individual datasets used for sample selection are described in more detail below.

\subsubsection{CALIPSO}

Aerosol vertical distribution, cloud-top height, cloud-base height, cloud optical depth, and initial approximate cloud phase were obtained from the polar-orbiting CALIPSO satellite lidar v. 3.01 level $2,5 \mathrm{~km}$ aerosol profile and cloud layer products products (CALIPSO Science Team, 2015a, b) at $532 \mathrm{~nm}$. These data have a vertical resolution of $30 \mathrm{~m}$ within layer (up to $8 \mathrm{~km}$ ), where most predominantly liquid Arctic Ocean clouds were found. Before averaging, along-track cloud profile data were collected at a horizontal resolution of $1 / 3 \mathrm{~km}$. Averaged aerosol data have a horizontal resolution of between 5 and $80 \mathrm{~km}$, with the horizontal resolution increasing with aerosol concentration. For example, in clear air with no detected aerosols, the horizontal resolution is $80 \mathrm{~km}$; in strong aerosol layers, the horizontal resolution providing an adequate signal-to-noise ratio can be as low as $5 \mathrm{~km}$ (Vaughan et al., 2009).

Because our samples were taken at night, Moderate Resolution Imaging Spectroradiometer (MODIS) optical depths were not available. Instead, the CALIPSO product was used to measure CODs, as it offers substantially higher data availability in the optical thickness range of interest $(\mathrm{COD}<3)$ than CloudSat (Christensen et al., 2013). Only non-qualityflagged (i.e., the highest quality) CALIPSO COD data were used. CALIPSO cloud optical depth uncertainties rise with COD due to uncertainties in the lidar ratio in liquid clouds with COD $>1$ (CALIPSO Quality Statements: Lidar Level 2 Cloud and Aerosol Layer Products, Version Releases: 3.01, 3.02). We excluded COD data with uncertainties $\geq 75 \%$ of the COD value (these constituted $\sim 5 \%$ of all cases).

Because it can be difficult to accurately separate Arctic aerosol from diamond dust and thin ice clouds using backscatter data (M. Vaughan, personal communication; 2016; Grenier and Blanchet, 2010), we focused on CALIPSO liquid-containing clouds. To gain greater confidence in the aerosol classification within the MOONLiT subset, ice clouds were not allowed in those profiles. Note that CALIOP cloud phase indicates only whether the cloud predominantly contained liquid or ice; there is no mixed-phase designation. At a later step, CloudSat data were used to further refine cloud-phase information.

CALIPSO data were obtained over the Arctic Ocean between 60 and $82^{\circ} \mathrm{N}$ and between 1 January 2008 and 7 December 2009 (during the latter part of CloudSat epoch 2). To obtain the lowest possible comparable detection limit, the analysis was restricted to nighttime clouds. Here, nighttime profiles are taken in the CALIPSO orbit over the hemisphere of Earth that is dark at any given time, and so the borders of this hemisphere may include some low-light conditions. MOONLiT clouds were additionally restricted to upper-layer clouds only. We focused on ONLi clouds present between 0.2 and $8 \mathrm{~km}$ above the surface to enable better below-cloud aerosol detection. MOONLiT cloud cases were further restricted to above $1 \mathrm{~km}$ for better comparison to high-quality CloudSat data. Very few predominantly liquid clouds are expected above $8 \mathrm{~km}$. Clouds were included only when the feature's optical properties scored between 70 and 100 in the cloud-aerosol discrimination (CAD) algorithm (a high confidence cloud determination) (Liu et al., 2009). The lidardetermined presence of a below-cloud aerosol layer was a key criterion in identifying clean background clouds with confidence, as discussed further in Sect. 3.1. Thus, the analysis was limited to non-opaque clouds (COD $<\sim 3$ ), as determined by the $532 \mathrm{~nm}$ extinction quality control flag.

The clean background cloud subset met the criteria above, but no aerosol features were permitted above or below cloud, even when air masses had been horizontally averaged across $80 \mathrm{~km}$ resolution in the CALIPSO aerosol detection algorithm, which is the resolution that detects weak aerosol layers with highest confidence. Given these constraints, the backscatter aerosol detection limit for clean background clouds is as low as possible and should have only negligible variations based on detector noise and background molecular scattering and $\mathrm{O}_{3}$ densities above cloud (Vaughan et al., 2009). Because CALIPSO cannot always detect dilute aerosols (Di Pierro et al., 2013; Kacenelenbogen et al., 2014; Rogers et al., 2014; Winker et al., 2013), particularly below cloud where the lidar signal has been reduced, clean background clouds were also required to have modeled above- and below-cloud FLEXPART (FLEXible TRAjectory model; Stohl et al., 1998, 2005) black carbon concentrations of $<30 \mathrm{ng} \mathrm{C} \mathrm{m}^{-3}$ (see Sects. 2.1.3 and 3.1 for further discussion). The aerosol-influenced subset had aerosols with CAD scores between -100 and -70 (high-confidence aerosol classification) above or below the cloud and FLEXPART modeled below-cloud black carbon (BC) concentrations of $>30 \mathrm{ng} \mathrm{C} \mathrm{m}^{-3}$. The geographical distributions of the all-cloud, clean cloud, and aerosol-influenced cloud sets are shown in Fig. 1.

\subsubsection{CloudSat}

CloudSat cloud profiling radar data are collected at a vertical resolution of $240 \mathrm{~m}$. CloudSat has a wider swath than CALIPSO $(1.4 \times 1.8 \mathrm{~km})$ and it takes measurements on the same polar orbit, only seconds ahead of CALIPSO. Because the CloudSat radar does not accurately estimate cloud properties below $\sim 0.7-1 \mathrm{~km}$ a.g.l. (Huang et al., 2012; Mioche et al., 2015), CloudSat data were provided only for clouds with bases $\geq 0.75 \mathrm{~km}$ a.g.l. Some of the very thin clouds de- 
Table 1. Criteria used for cloud and air mass classification.

\begin{tabular}{|c|c|c|c|c|c|c|c|}
\hline Data source type & $\begin{array}{l}\text { ONLi clean } \\
\text { clouds }\end{array}$ & $\begin{array}{l}\text { ONLi all } \\
\text { clouds }\end{array}$ & $\begin{array}{l}\text { ONLi aerosol- } \\
\text { influenced clouds }\end{array}$ & $\begin{array}{l}\text { MOONLiT clean } \\
\text { clouds }\end{array}$ & $\begin{array}{l}\text { MOONLiT all } \\
\text { clouds }\end{array}$ & $\begin{array}{l}\text { MOONLiT aerosol- } \\
\text { influenced clouds }\end{array}$ & $\begin{array}{l}\text { Clear } \\
\text { air }\end{array}$ \\
\hline \multicolumn{8}{|l|}{ CALIPSO v. $3.01 \mathrm{~L} 2532 \mathrm{~nm}$ aerosol profile data } \\
\hline Latitude: $60-82^{\circ} \mathrm{N}$ & $\mathrm{x}$ & $\mathrm{x}$ & $\mathrm{x}$ & $\mathrm{x}$ & $\mathrm{x}$ & $\mathrm{x}$ & $\mathrm{x}$ \\
\hline Nighttime & $\mathrm{x}$ & $\mathrm{x}$ & $\mathrm{x}$ & $\mathrm{x}$ & $\mathrm{x}$ & $\mathrm{x}$ & $\mathrm{x}$ \\
\hline Uppermost cloud layer only & & & & $\mathrm{x}$ & $\mathrm{x}$ & $\mathrm{x}$ & \\
\hline Cloud-top altitude $<8 \mathrm{~km}$ a.s.l. & $\mathrm{x}$ & $\mathrm{x}$ & $\mathrm{x}$ & $\mathrm{x}$ & $\mathrm{x}$ & $\mathrm{x}$ & \\
\hline Cloud-base altitude $>0.2 \mathrm{~km}$ a.s.1. & $\mathrm{x}$ & $\mathrm{x}$ & $\mathrm{x}$ & & & & \\
\hline Cloud-base altitude $>1 \mathrm{~km}$ a.s.1. & & & & $\mathrm{x}$ & $\mathrm{x}$ & $\mathrm{x}$ & \\
\hline $\mathrm{COD}<\sim 3$ (no extinction quality control flag) & $\mathrm{x}$ & $\mathrm{x}$ & $\mathrm{x}$ & $\mathrm{x}$ & $\mathrm{x}$ & $\mathrm{x}$ & \\
\hline In-cloud CAD score between 70 and 100 & $\mathrm{x}$ & $\mathrm{x}$ & $\mathrm{x}$ & $\mathrm{x}$ & $\mathrm{x}$ & $\mathrm{x}$ & \\
\hline CALIPSO liquid-phase only & $\mathrm{x}$ & $\mathrm{x}$ & $\mathrm{x}$ & $\mathrm{x}$ & $\mathrm{x}$ & $\mathrm{x}$ & \\
\hline No cloud-phase quality control flags & $\mathrm{x}$ & $\mathrm{x}$ & $\mathrm{x}$ & $\mathrm{x}$ & $\mathrm{x}$ & $\mathrm{x}$ & \\
\hline No aerosol above cloud & $\mathrm{x}$ & & & $\mathrm{x}$ & & & \\
\hline Aerosol observed above or below cloud & & & $\mathrm{x}$ & & & $\mathrm{x}$ & \\
\hline $\begin{array}{l}\text { No aerosol between cloud base and surface or } \\
\text { next cloud top, whichever comes first }\end{array}$ & $\mathrm{x}$ & & & $\mathrm{x}$ & & & \\
\hline Aerosol CAD score between -100 and -70 & & & $\mathrm{x}$ & & & $\mathrm{x}$ & \\
\hline No clouds or aerosol anywhere in profile & & & & & & & $\mathrm{x}$ \\
\hline No absolute profile CAD score values $<70$ & & & & $\mathrm{x}$ & $\mathrm{x}$ & $\mathrm{x}$ & \\
\hline No ice allowed anywhere in profile & & & & $\mathrm{x}$ & $\mathrm{x}$ & $\mathrm{x}$ & \\
\hline \multicolumn{8}{|l|}{ FLEXPART model output } \\
\hline $\mathrm{BC} \leq 30 \mathrm{ng} \mathrm{C} \mathrm{m}^{-3}$ & $\mathrm{x}$ & & & $\mathrm{x}$ & & & \\
\hline $\mathrm{BC} \geq 30 \mathrm{ng} \mathrm{Cm}^{-3}$ & & & $\mathrm{x}$ & & & $\mathrm{x}$ & \\
\hline \multicolumn{8}{|l|}{ CloudSat 2B-CLDCLASS-lidar data* } \\
\hline$>750 \mathrm{~m}$ aboveground & $\mathrm{x}$ & $\mathrm{x}$ & $\mathrm{x}$ & $\mathrm{x}$ & $\mathrm{x}$ & $\mathrm{x}$ & \\
\hline Non-precipitating clouds & $\mathrm{x}$ & $\mathrm{x}$ & $\mathrm{x}$ & $\mathrm{x}$ & $\mathrm{x}$ & $\mathrm{x}$ & \\
\hline Liquid- or mixed-phase only & $\mathrm{x}$ & $\mathrm{x}$ & $\mathrm{x}$ & $\mathrm{x}$ & $\mathrm{x}$ & $\mathrm{x}$ & \\
\hline Liquid-phase only (for $r_{\mathrm{el}}$ measurements) & $\mathrm{x}$ & $\mathrm{x}$ & $\mathrm{x}$ & $\mathrm{x}$ & $\mathrm{x}$ & $\mathrm{x}$ & \\
\hline
\end{tabular}

tected by CALIPSO had radar reflectivities that were too low to be detected by CloudSat, and CloudSat may sometimes mistakenly assign precipitating ice as a cloud (de Boer et al., 2008). Therefore, radar reflectivity data and CloudSat reflectivity-derived cloud parameters, where available, were obtained from the height bins closest to where CALIPSO detected a cloud.

Average reflectivity between the CALIPSO-determined cloud top and base was obtained from the CloudSat 2BGEOPROF version R04 dataset. Cloud phase and precipitation occurrence were acquired from 2B-CLDCLASSlidar version R04 estimates (Wang, 2013). In this product, cloud phase is determined from a combination of CALIPSO water layer detection and integrated backscattering coefficient, temperature, CloudSat reflectivity, and an assumed temperature-dependent reflectivity threshold for ice particles (Zhang et al., 2010). This phase classification is uncertain for clouds with reflectivities of $<-29 \mathrm{dBZ}$ (the CloudSat sensitivity limit) and for very thin clouds due to the coarse vertical resolution of the instrument. As we focused on cold, optically thin clouds in this study, many $(\sim 29 \%)$ of our samples were below the CloudSat detection limit. Thus, phase was only assessed in clouds with cloud-phase certainty values of $>5$ and with reflectivity values of $>-29 \mathrm{dBZ}$. Infrequently, clouds that met the CALIPSO criterion in Table 1 were classified as predominantly ice phase by the 2B-CLDCLASSlidar product; these cases were excluded from the analysis for simplicity, despite the potential for supercooled water to be misclassified as ice particles (Van Tricht et al., 2016).

Estimated mean liquid cloud droplet effective radii $\left(r_{\mathrm{el}}\right)$ were obtained from the CloudSat 2B-CWC-RO version R04 product (LO_RO_effective_radius) (Austin and Stephens, 2001). We chose this CloudSat $r_{\mathrm{el}}$ product, which assumes that all particles are liquid, for two reasons: (1) CALIPSO had independently assigned the clouds a predominantly liquid phase, and (2) uncertainties in the other liquid $r_{\mathrm{el}}$ data product available for nighttime samples (RO_liq_effective_radius) may be fairly high because of a reliance on an overly simplistic, temperature-dependent phase partitioning scheme (e.g., de Boer et al., 2008; Lee et al., 2010). Where available, $r_{\mathrm{el}}$ data were averaged over vertical regions within the CALIOP-determined liquid-phase cloud base and top. Sometimes the corresponding CloudSatdetermined cloud base and top were slightly different. In these cases, CALIOP heights were used because of their better ability to detect liquid droplets, and because CloudSat may sometimes misclassify precipitating ice as part of the cloud (de Boer et al., 2008), which can lead to overestimation of $r_{\mathrm{el}}$. Quality-flagged data, such as observations from precipitating clouds, were excluded as determined from the CloudSat 2B-CLDCLASS-lidar version R04 product. Note that although we counted the number of cases where precipitation occurred for comparison at a different step, precipitating cases were otherwise excluded from most other derived 

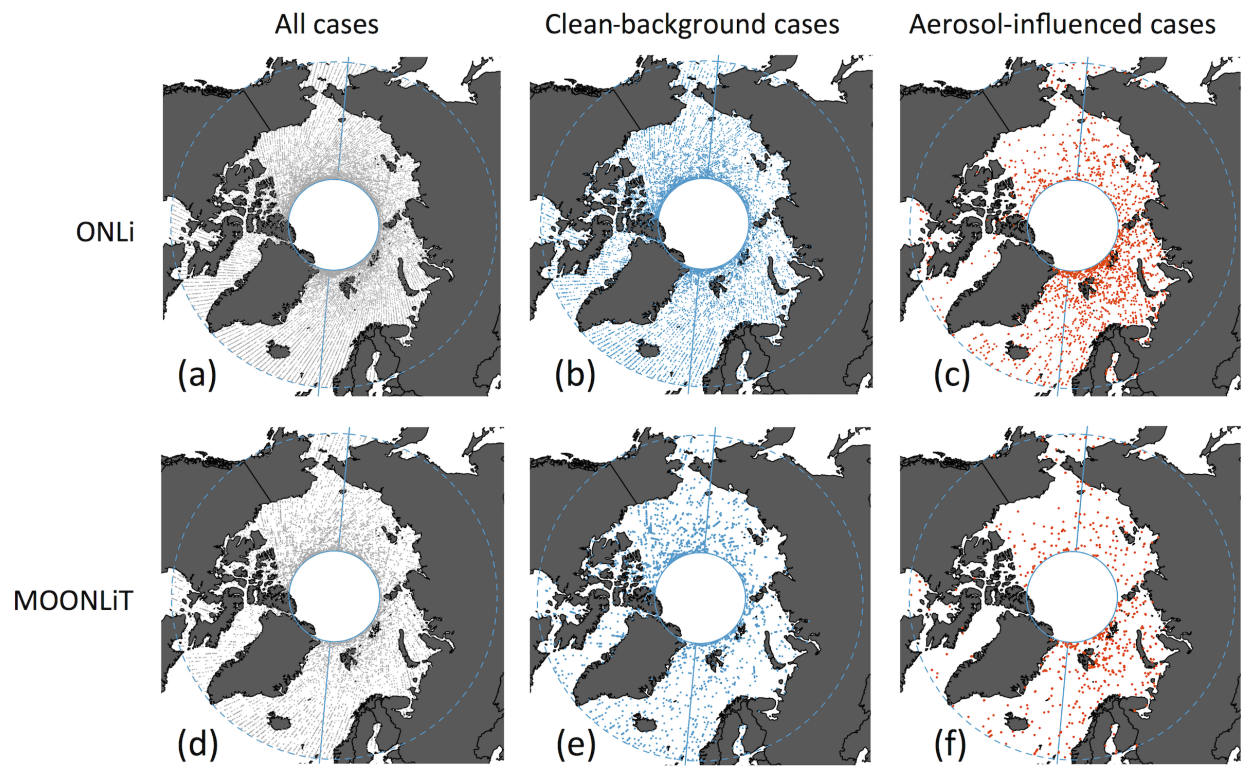

Figure 1. The geographical distribution of ONLi and MOONLiT cloud profiles, where (a, d) grey indicates all cases, (b, e) blue indicates clean background cases, and (c, f) red indicates aerosol-influenced cases.

cloud parameters in the analysis. These cases were excluded in order to obtain comparable data across cloud characteristics, which was particularly important for the longwave emissions calculations detailed in Sect. 2.2 that included the $r_{\mathrm{el}}$ as one of several input parameters.

We present some limited CloudSat-derived $r_{\mathrm{el}}$ data here, but it is important to note the fairly high uncertainties in some of these data. Aside from the assumption of liquid phase, there is a known bug in the CloudSat code that might cause $r_{\mathrm{el}}$ in liquid clouds to be overestimated, and to our knowledge there has been no extensive validation of the CloudSat 2B-CWC-RO $r_{\mathrm{el}}$ product in the Arctic. De Boer et al. (2008) found fairly reasonable agreement, with perhaps some overestimation, between CloudSat-determined $r_{\mathrm{el}}$ in mixed-phase clouds compared to $r_{\mathrm{el}}$ measured from ground-based instruments. However, only a few samples were collected with the in-cloud constraint in that study. The cumulative uncertainties in $r_{\mathrm{el}}$ on the radiative impact results are discussed further in Sect. 3.5.

\subsubsection{FLEXPART}

The locations of combustion aerosol plumes were modeled using BC from the FLEXPART model (Stohl et al., 1998, 2005). The FLEXPART model has been used extensively to study pollution and smoke transport in the Arctic, and is well-validated for this purpose (Damoah et al., 2004; Eckhardt et al., 2015; Forster et al., 2001; Paris et al., 2009; Sodemann et al., 2011; Stohl et al., 2002, 2003, 2015). We chose $\mathrm{BC}$ as a combustion aerosol tracer because it represents aerosol removal better than a gaseous tracer like carbon monoxide and because FLEXPART can largely capture the Arctic BC seasonal cycle (Eckhardt et al., 2015) that is driven by a combination of seasonal changes in emissions, atmospheric transport patterns, and removal processes. In some cases, wildfires can emit large amounts of light-absorbing organic carbon aerosols (or brown carbon) without emitting large amounts of BC (e.g., Chakrabarty et al., 2016). In these cases, FLEXPART BC may not represent smoke aerosols well.

For this study, as in Eckhardt et al. (2015), FLEXPART was driven with meteorological analysis data from the European Centre for Medium-Range Weather Forecasts (ECMWF) at a resolution of $1^{\circ}$ longitude and $1^{\circ}$ latitude. $\mathrm{BC}$ emissions were based on the ECLIPSE emission inventory (Stohl et al., 2015), which also includes emissions from gas flaring, and biomass burning emissions. In the model simulations, $\mathrm{BC}$ was removed from the atmosphere through dry deposition, and wet scavenging both below and within clouds. However, no transformation of BC from a hydrophobic to a hydrophilic state was considered and removal parameters were chosen as typical for a hydrophilic aerosol. FLEXPART-modeled BC concentrations were calculated for the years 2008 and 2009 at a horizontal resolution of $1^{\circ}$ latitude and $2^{\circ}$ longitude and at 0.05, 0.2, 1, 2, 3, 5, 7, and $10 \mathrm{~km}$ a.g.1. Below-cloud $\mathrm{BC}$ concentrations were taken to be the closest modeled concentration available to $0.5 \mathrm{~km}$ below cloud base. When there were multilayer clouds and the next cloud top was $<1 \mathrm{~km}$ away, the concentration closest to the middle distance between the two clouds was used instead. 


\subsection{Ancillary datasets}

Aircraft out-of-cloud BC data were obtained from NASA's Arctic Research of the Composition of the Troposphere from Aircraft and Satellites (ARCTAS) campaign (Fuelberg et al., 2010; Jacob et al., 2010; Kondo et al., 2011). The aircraft data with the highest aerosol particle concentrations were clustered between 50 and $60^{\circ} \mathrm{N}$ during this campaign. Thus, we included aircraft data from between 50 and $82^{\circ} \mathrm{N}$ (subarctic and Arctic) in order to assess comparable ranges of dilute and concentrated aerosols expected to be present over the Arctic. Submicron aerosol dry size distributions between 0.06 and $1 \mu \mathrm{m}$ were measured from a Droplet Measurement Technologies ultra-high-sensitivity aerosol spectrometer (UHSAS) between 0 and $2.1 \mathrm{~km}(2.9 \mathrm{~km}$ for springtime samples). Submicron aerosol scattering data at $532 \mathrm{~nm}$ were obtained from a Radiance Research (RR) nephelometer and were corrected for truncation errors. Submicron aerosol scattering coefficients at 450 and $700 \mathrm{~nm}$ were estimated as the difference between total scattering from a TSI 3563 integrating nephelometer and the RR nephelometer when the finemode aerosol fraction exceeded 0.6. Ambient total scattering coefficients at the three wavelengths were obtained from the TSI nephelometer and were corrected for truncation errors following Anderson and Ogren (1998). Aerosol absorption coefficients at 450,532 , and $700 \mathrm{~nm}$ were measured with a RR three-wavelength particle soot absorption photometer (PSAP).

An aircraft-derived, $180^{\circ}$ backscatter coefficient is calculated following Sawamura et al. (2017) in order to compare the in situ data to those from CALIOP (units of $\mathrm{Mm}^{-1} \mathrm{sr}^{-1}$ ). First, the dry submicron aerosol size distribution, scattering coefficient, and absorption coefficient measured at $532 \mathrm{~nm}$ are input into a Mie theory model to determine the aerosol effective dry refractive index. Next, a hygroscopic growth factor was applied to the dry size distribution in the Mie theory model to reproduce observed humidified light scattering and thus derive the aerosol refractive index at ambient relative humidity. The $180^{\circ}$ backscatter coefficient then follows from Mie theory using the adjusted size distribution and refractive index. This method is best suited for spherical particles, which we assume dominate the ARCTAS samples based on the main aerosol sources during the campaign (non-dust background aerosols, anthropogenic pollution, and smoke; Jacob et al., 2010).

Several other supplemental datasets were used for cloud environmental context. ETOPO1 Bedrock GMT4 data (Amante and Eakins, 2009) were used to identify cloud profiles over the Arctic Ocean region. NOAA/NSIDC Climate Data Record of Passive Microwave Sea Ice Concentration, version 2 data (Meier et al., 2013; Peng et al., 2013) were used to approximate the fractional sea ice cover over ocean in the specific month and at the specific location of each profile. A sample was classified as being primarily over sea ice or open ocean when the sea ice fraction at the given location and in the given month was $>80 \%$ or $<20 \%$, respectively.

Lastly, integrated surface longwave $(4-30 \mu \mathrm{m})$ radiation was calculated with an updated Santa Barbara DISTORT Atmospheric Radiative Transfer program (SBDART; Ricchiazzi et al., 1998). Shortwave effects are not expected to be significant during nighttime conditions. Following McComiskey and Feingold (2008), the calculations assume homogeneous cloud cover and spectrally uniform surface albedo. Median surface longwave reflectivity $(R)$ for open ocean and sea ice in clear conditions with no clouds or aerosols ( 0.64 and 0.69 , respectively) was calculated from MERRA-2 output (GMAO, 2015) based on the times and locations of the data and the following formula (Josey et al., 2003):

$R=1-\frac{E-A}{I}$,

where $E$ is the emitted longwave radiation from the surface, $A$ is the net longwave flux into the surface from the atmosphere, and $I$ is the downwelling longwave radiation from the atmosphere. Note that the $A$ parameter above is proxied by the closest available parameter in the MERRA-2 output, surface-absorbed longwave radiation, and thus it does not include factors such as transmission, latent heat, or conduction and convection. Because even a $50 \%$ change in $R$ would lead to $<1 \%$ error in the cloud longwave surface flux calculations, we expect the resulting uncertainty in $R$ to have a negligible impact on our results.

\section{Results and discussion}

\subsection{Correct identification of clean background conditions}

To accurately characterize clean background conditions, it is necessary to detect combustion-related aerosol layers with confidence. For CALIPSO, dilute aerosols are least likely to be detected below cloud due to signal attenuation inside the cloud (Di Pierro et al., 2013), but CALIOP can sometimes miss dilute aerosol layers even in clear air above clouds ( $\mathrm{Di}$ Pierro et al., 2013; Kacenelenbogen et al., 2014; Rogers et al., 2014; Sheridan et al., 2012; Winker et al., 2013). Most previous works focused either on daytime samples, which have comparatively low signal-to-noise ratios, or on extinction data, which are more uncertain because they assume a prescribed lidar ratio. To begin quantifying the false negative rate relevant to this study, we used two independent methods to estimate the fraction of the time when nighttime Arctic CALIPSO data would not detect above-cloud aerosols when actually present.

First, we estimated the fraction of air masses containing various observed concentrations of aerosol tracers that would be detected at the reported theoretical $80 \mathrm{~km}$ resolution nighttime backscatter detection limit from Winker et al. (2009). 
This analysis is based on co-located aircraft backscatter, particle number, and BC data from the ARCTAS aircraft campaign (Fig. 2a). The results suggest that CALIOP would miss $\sim 36 \%$ of slightly polluted air masses (i.e., BC concentrations $>30 \mathrm{ng} \mathrm{m}^{-3}$ ) at $80 \mathrm{~km}$ resolution in nighttime air masses not below another feature. This estimate might be affected by errors from assuming Mie theory and a theoretical detection limit that may not be perfectly representative in the field, as well as errors caused by a limited number of field data from scattered locations.

As an independent consistency check, we next determined the frequency at which aerosols were detected by both FLEXPART and CALIOP. To do so, we compared the fraction of observed clear-sky (no-cloud) CALIOP profiles that were expected to contain aerosols at different simulated FLEXPART aerosol concentrations for January 2008 (Fig. 2b). These results suggested that CALIOP may not have detected up to $\sim 33 \%$ of slightly polluted air masses $\left(\mathrm{BC}>30 \mathrm{ng} \mathrm{m}^{-3}\right)$ above cloud, although this value likely overestimates the actual false negative rate given inherent model errors. This independent estimate is fairly similar to the previously estimated false negative rate, and so we expect the real-world above-cloud CALIOP false negative rate for dilute aerosols to be $\sim 33-36 \%$. Below-cloud errors would be higher but are more difficult to quantify because of the variability in in-cloud attenuation.

Based on CALIPSO criteria alone, the estimates above suggest that aerosol detection uncertainties may be higher than desirable, particularly below cloud. We address this issue in two ways. First, we apply the criteria for determining clean background cloud that depend not only on aerosol-free CALIPSO profiles but also on modeled above- and belowcloud BC concentrations of $<30 \mathrm{ng} \mathrm{m}^{-3}$ (see Sect. 2.1.3). We expect the model aerosol-occurrence criterion to substantially improve the classification confidence because coincidences of false negatives in both the CALIOP data and the model are likely to be rare (they are most likely to occur in dilute aerosol conditions). As such, this method should correctly identify clean background clouds much more frequently than $64-67 \%$ of the time. Unfortunately, further quantification in the classification confidence is difficult because both model accuracy and the degree of below-cloud lidar attenuation are variable in time and space. Secondly, we assess the MOONLiT cloud subset along with ONLi cloud results. MOONLiT clouds are a subset of ONLi clouds that, among other criteria meant to enhance certainty in aerosol layer identification, are in the top layer (see Sect. 2.1 and Table 1 for more details). Trends in MOONLiT cloud results are mainly noted only if they are dissimilar to those in the larger ONLi cloud group and are otherwise provided in the Supplement. To our knowledge, the combined CALIPSO and model criteria used here allow the most confident classification of background conditions currently possible for remote sensing studies of the Arctic.

\subsection{Notes on limitations imposed by the methods}

In order to have greater confidence in quantifying the regional-scale aerosol indirect effects, this study is limited to ONLi clouds and their MOONLiT cloud subset. It is important to emphasize that the ONLi cloud group is not representative of all Arctic clouds. During our study period, ONLi clouds were present in only $5.3 \%$ of all total comparable nighttime cloudy profiles over the Arctic Ocean (comparable clouds defined as having a satisfactory in-cloud CAD score of 70-100 and with cloud bases $>200 \mathrm{~m}$ to exclude fog). Liquid-dominated clouds tend to be found at lower altitudes than thicker opaque clouds and may thus not always be identified in multilayer clouds using CALIPSO. However, even though the actual prevalence of these clouds may be somewhat underestimated, it is clear that ONLi clouds represent just a small fraction of all Arctic clouds. Thus, we emphasize that the aerosol indirect responses described in this paper are not necessarily representative of Arctic clouds in general.

Moreover, the cloud-selection criteria imposed by our methods may induce some uncertainties in the analysis. For example, due to the low COD constraint, it is possible that some fraction of the cloud subset influenced by aerosols may be selected from a different group of cloud types than some fraction of the clean background cloud subset. As an illustration, in a subarctic aircraft case study presented in Zamora et al. (2016) (see Appendix A for further details), cumulus clean background clouds with an observed cloud thickness of $\sim 250 \mathrm{~m}$ had CODs of $\sim 5$. These clouds would have been too optically thick for the CALIOP lidar to penetrate. However, highly comparable nearby clouds in a smoke plume had CODs of only $\sim 2$. The cloud-property differences were likely driven by the aerosol (Zamora et al., 2016). In this example, only the subset of clouds influenced by smoke aerosols would have met this study's COD criterion and not the clean background cloud counterparts. Median reductions in COD were fairly minor for aerosol-impacted clouds relative to background clouds and were not significant over open ocean, and so we do not expect this effect to have a large impact on our study.

Similarly, any aerosol-driven phase changes that shifted clouds between predominantly ice- and liquid-containing clouds (e.g., Girard et al., 2013) could have eliminated samples from or added samples to our study, also potentially adding some bias to our results. These uncertainties are difficult to quantify but are likely to be much smaller than the error that would be introduced by expanding the dataset to include other non-ONLi cloud subsets that would be characterized with greater uncertainty.

\subsection{ONLi cloud characteristics in clean marine background conditions}

In our study, sampled clouds were thin by definition and were thus unlikely to occur under very turbulent conditions. The 

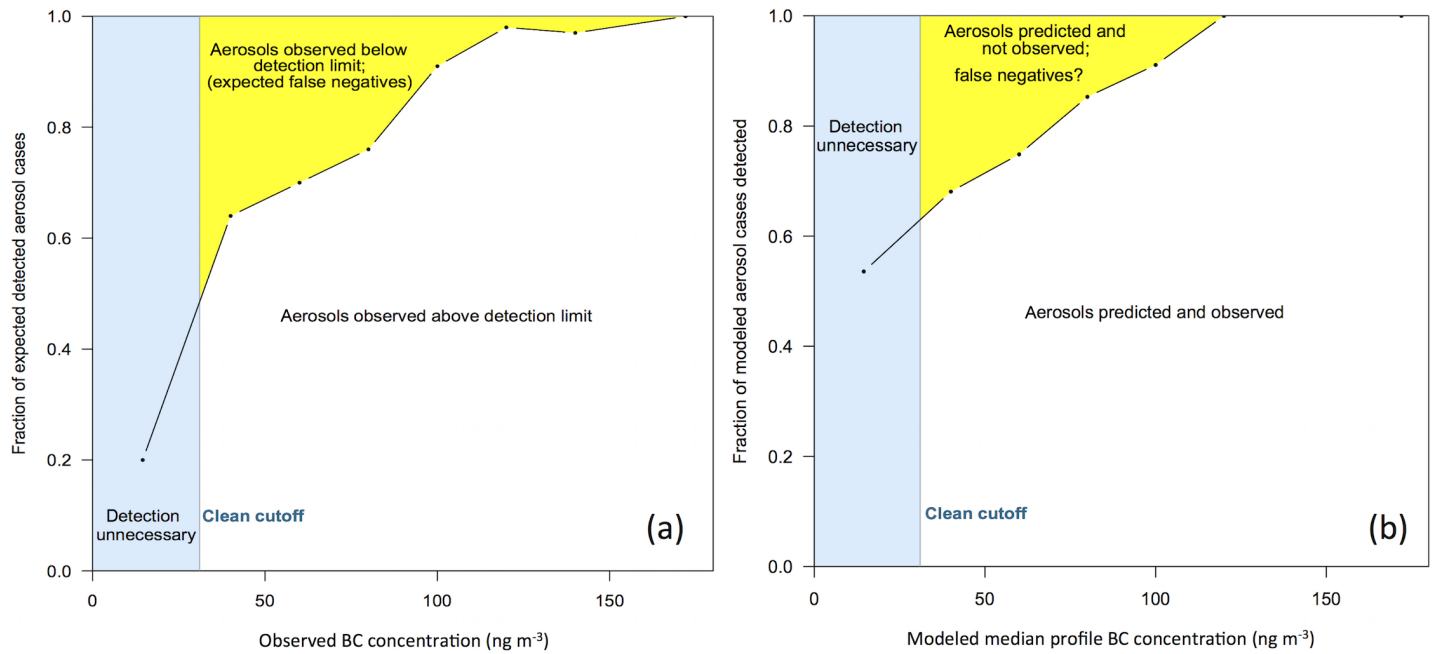

Figure 2. Based on CALIPSO Arctic profiles under non-cloudy conditions, we compare (a) the expected fraction and (b) possible maximum fraction of false negatives (aerosol present but not detected) for the combustion tracer black carbon $\left(\mathrm{BC}, \mathrm{ng} \mathrm{C} \mathrm{m}^{-3}\right.$ ). The expected fraction of false negatives in panel (a) was determined by comparing binned out-of-cloud 2008 ARCTAS-A and ARCTAS-B BC concentrations with the fraction of the total number of samples between 1 and $5 \mathrm{~km}$ that had converted backscatter values $\left(\mathrm{Mm}^{-1} \mathrm{sr}^{-1}\right.$ ) above the CALIPSO clear-sky nighttime backscatter detection limit from Winker et al. (2009) (see text for more details). Possible maximum false negative values in panel (b) were determined by comparing the FLEXPART model's median BC concentrations between 0 and $10 \mathrm{~km}$ with the fraction of the total CALIPSO profiles under non-cloudy conditions during January 2008 where aerosols were not detected. The clean cutoff below which air is taken as clean is assumed to be $30 \mathrm{ng} \mathrm{BC} \mathrm{m}^{-3}$.

range in turbulence covered in the sample set was also likely limited during polar night due to the lower variability in external heating and generally high static stability of the Arctic atmosphere. Nonetheless, we expect that clouds over the open ocean are impacted more by thermodynamic coupling with the surface (Shupe et al., 2013) than over sea ice, where surface-based inversions occur more frequently (Ganeshan and $\mathrm{Wu}, 2015)$. In this study, we stratify clouds into these two regimes to distinguish the effects of systematic differences in atmospheric stability and large-scale atmospheric and surface forcing between the two systems (Curry et al., 1996; Jaiser et al., 2012; Taylor et al., 2015).

ONLi clouds were more likely to overlay another cloud layer over open ocean than over sea ice, as demonstrated by the average height of the next below-cloud feature (Fig. 3b, Table 2). A similar result was also observed previously at the SHEBA ship-based observatory (Intrieri et al., 2002) and for general cloud aggregates over the Arctic ( $\mathrm{Li}$ et al., 2015). There are also differences between shallow and higher clouds. Shallow clouds are defined here as having cloud bases $<1.1 \mathrm{~km}$ a.s.l., based on the lower quartile range of the cloud-base height data. Over both open ocean and sea ice, shallow clouds are warmer and are more likely to have a liquid- vs. mixed-phase CloudSat designation (Tables S1 and S2 in the Supplement). Shallow clouds are on average optically thicker, but geometrically thinner, than higher clouds. They are also less likely to be observed in multilayer cloud conditions in both regimes $(p<0.05$, permutation test), which may be due in part because they are sys- tematically less observable due to lidar attenuation in higher thick cloud layers.

It is possible that some of the differences between shallow and high ONLi clouds are due to differences in cloud formation mechanisms. For example, previous studies suggest that shallow liquid-containing Arctic clouds might form from the advection of warm, moist air over a cool surface, whereas higher liquid-containing clouds might form from a longwave radiative flux divergence (Smith and Kao, 1995) or partial dissolution of a higher-level stratus cloud (Herman and Goody, 1976). One previous model sensitivity study linked shallow liquid-containing clouds in a 3-day Arctic multilayer cloud system with surface turbulent heat fluxes, and overlying liquid-containing clouds with large-scale advection and maintenance by radiative cooling (Luo et al., 2008). Because of these differences, shallow ONLi clouds were characterized separately in later analysis in order to better understand the influence of confounding meteorological factors on the results.

The different probabilities of cloud-layering occurrence over sea ice vs. open ocean and in cloud properties over different heights complicates comparisons between the two regimes. However, comparing only single-layer clouds with bases above $1.1 \mathrm{~km}$, the median cloud-base height of openocean clouds is $\sim 240 \mathrm{~m}$ higher $(\sim 480 \mathrm{~m}$ for MOONLiT clouds) than for clouds over the sea ice ( $p<0.05$, permutation test). Autumn ship-based cloud observations in the Chukchi and Beaufort seas also show higher cloud bases over the open ocean (Sato et al., 2012; Young et al., 2016). 


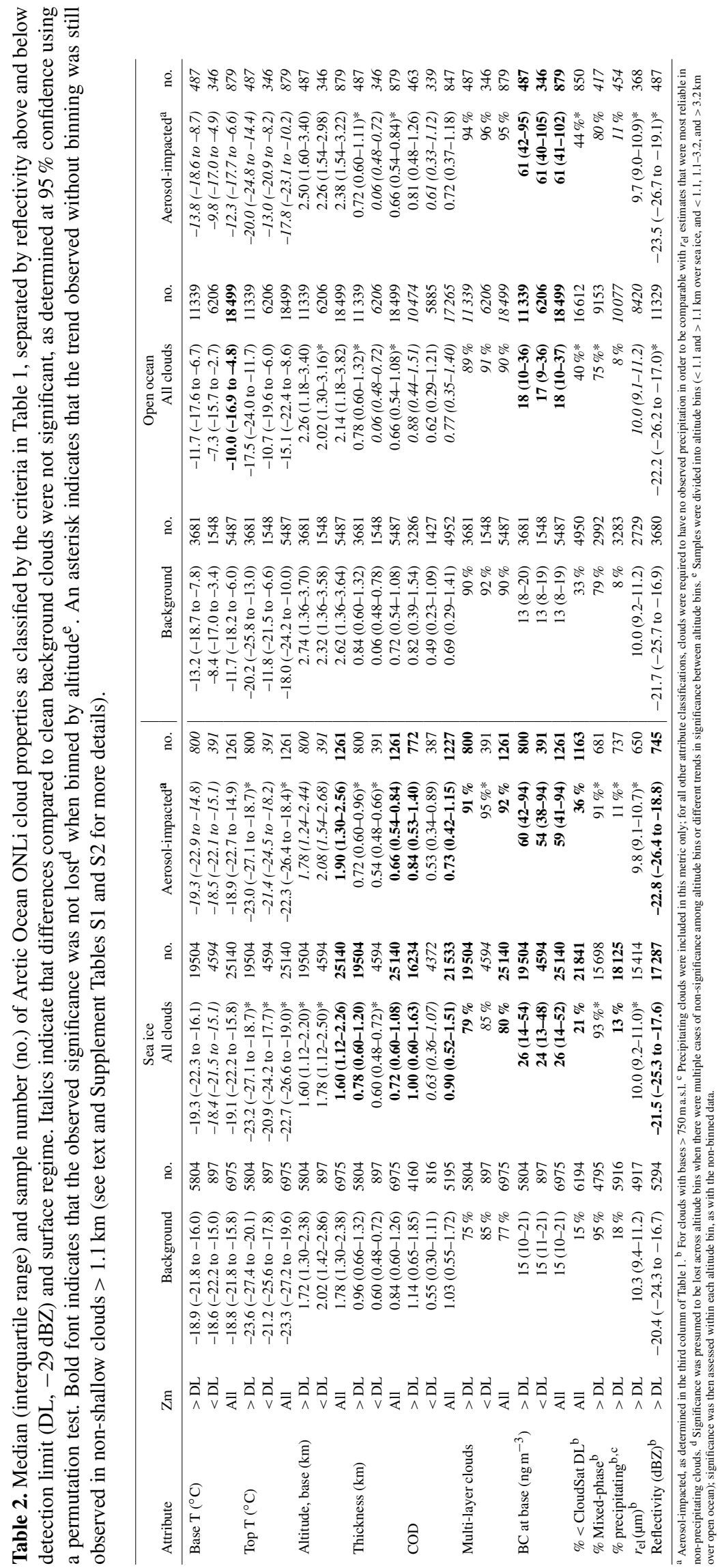



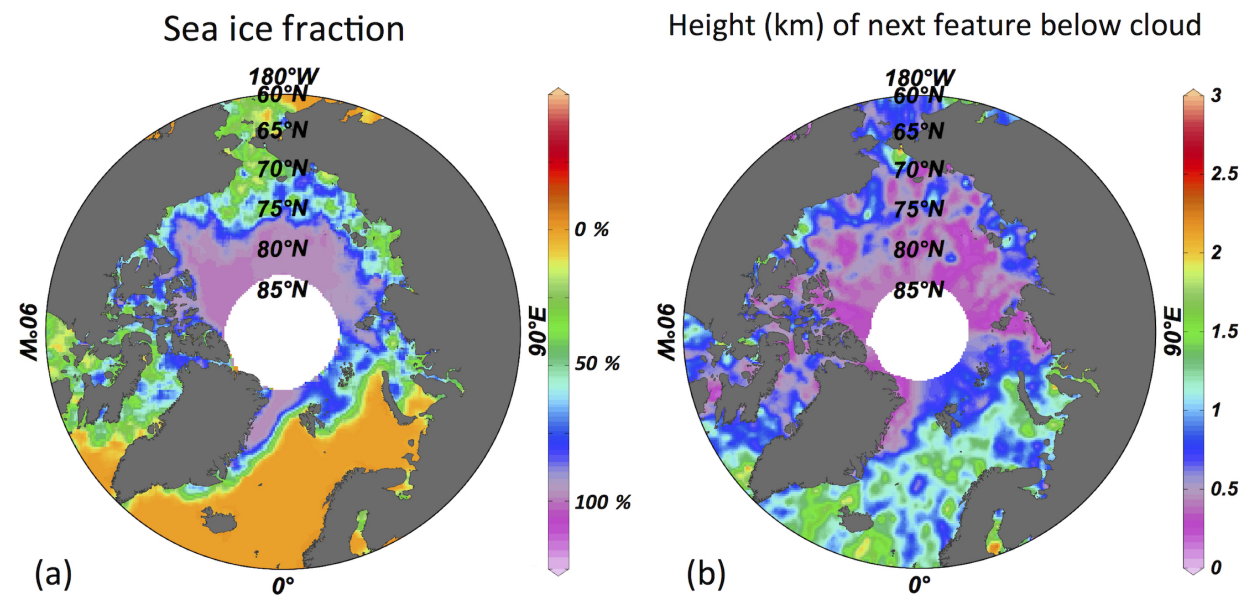

Figure 3. The weighted-average gridded maps of features below individual cloud points from Fig. 1b for (a) sea ice fraction, and (b) height of the next-lowest feature associated with individual cloud profiles, where a value of 0 indicates that the ocean surface or sea ice was the next-lowest feature. Over open ocean, ONLi clouds were much more likely to overlay another cloud than over sea ice.

Over sea ice, the lower cloud heights and the presence of fewer multilayer ONLi clouds compared to the open ocean (Table 2) are likely related to the lower height and greater frequency of surface-based inversions over Arctic sea ice, which can reduce surface moisture fluxes to higher altitudes (Bradley et al., 1992; Ganeshan and Wu, 2015; Zhang et al., 2011). Below $1.1 \mathrm{~km}$, cloud-base heights for single-layer clouds are not significantly different between regimes.

Over the open ocean, clouds were also warmer than over sea ice, and a higher fraction of ONLi clouds were observed with very-low-layer mean reflectivity $\left(Z_{\mathrm{m}}\right)$, defined as $Z_{\mathrm{m}}<-29 \mathrm{dBZ}$ (the CloudSat detection limit) (Table 2, Fig. 4). The very low $Z_{\mathrm{m}}$ clouds are geometrically and optically very thin (Table 2). Previously observed relationships between $Z_{\mathrm{m}}$ and $r_{\mathrm{el}}$ suggest that the very low $Z_{\mathrm{m}}$ clouds also likely have smaller $r_{\mathrm{el}}$ values (Frisch et al., 2002).

Because reflectivity was fairly low within the thin, predominantly liquid cloud profiles that fit our criteria, and temperatures were generally between -1 and $-28^{\circ} \mathrm{C}$, in many cases it was difficult to know for certain which clouds were of mixed vs. liquid phase. Of the clouds that were assigned a high-confidence phase classification by CloudSat, most contained some ice particles (93\%, $n=5238$ for sea ice, and $79 \%, n=2992$ for open ocean). We believe it likely that a comparatively higher fraction of the very low- $Z_{\mathrm{m}}$ clouds were present in the liquid-only phase. First, these clouds had very low $Z_{\mathrm{m}}$ values (indicative of small particles), and at the same time they were independently assigned a predominantly liquid phase by CALIPSO. Secondly, their median temperatures were warmer than clouds with higher $Z_{\mathrm{m}}$ (by $\sim 1-3{ }^{\circ} \mathrm{C}$ over sea ice and nearly $1-7^{\circ} \mathrm{C}$ over comparable altitudes over open ocean; Table 2). In relation to this, low$Z_{\mathrm{m}}$ clouds were more than 2 times more likely to be found over open ocean than over sea ice (Table 2). Further study would be needed to fully verify phase for this cloud subset, but the indications that these clouds have higher liquid fractions are consistent with the observations that (a) Arctic liquid clouds tend to have smaller $r_{\mathrm{el}}$ values than mixed-phase clouds (Hobbs and Rangno, 1985; Lance et al., 2011; Lebo et al., 2008; Rangno and Hobbs, 2001), and (b) clouds over the open ocean (which were more likely to have very low $Z_{\mathrm{m}}$ values; Fig. 5a, d) are also more likely to contain liquid (Cesana et al., 2012).

\subsection{Aerosol impacts on clouds over sea ice}

We expect that the greater uniformity in surface and meteorological conditions over sea ice will increase the likelihood of being able to isolate aerosol impacts from meteorological noise, compared to the situation over the open ocean. Cloud characteristics were indeed fairly uniform over sea ice. We observed only minor differences in cloud-base height between ONLi clouds present in clean background conditions and all ONLi clouds (Table 2, Fig. 4). Above $1.1 \mathrm{~km}$, the cloud-base temperatures in clean background conditions were not significantly different from those in all air mass conditions. Below $1.1 \mathrm{~km}$, clean background clouds appear to be found in slightly warmer conditions (by $\sim 2{ }^{\circ} \mathrm{C}$ ) (Table $\mathrm{S} 1$ ).

Clean background clouds were significantly more likely to be precipitating than other clouds in both height bins (Table 2). This observation falls in line with aerosol-driven reductions in snowfall that have been predicted and observed previously, inside and outside of the Arctic (Albrecht, 1989; Borys et al., 2000, 2003; Girard et al., 2005; Lance et al., 2011; Lohmann et al., 2003; Mauritsen et al., 2011; Morrison et al., 2008). These observed reductions in precipitation are inconsistent with the glaciation indirect effect, in which ice formation would be expected to increase due to higher concentrations of combustion-related INPs (Lohmann and Feichter, 2005). The presence of aerosols is also corre- 


\begin{tabular}{|c|c|c|}
\hline & Sea Ice & Open Ocean \\
\hline Base $\mathrm{T}\left({ }^{\circ} \mathrm{C}\right)$ : & Not significant & $\left.\begin{array}{r}0 \\
-4 \\
-8 \\
-12 \\
-16\end{array}\right] \square$ \\
\hline Top $\mathrm{T}\left({ }^{\circ} \mathrm{C}\right)$ : & $\left.\begin{array}{l}-16 \\
-20 \\
-24 \\
-28\end{array}\right]+4$ & Not significant \\
\hline Altitude, base $(\mathrm{km})$ : & $\left.\begin{array}{l}3 \\
2 \\
1 \\
0\end{array}\right]$ & Not significant \\
\hline Thickness (km): & $\left.\begin{array}{l}1.2 \\
0.8 \\
0.4\end{array}\right]$ & $\left.\begin{array}{l}1.2 \\
0.8 \\
0.4\end{array}\right] \top 1$ \\
\hline COD: & $\left.\begin{array}{l}1.5 \\
1.0 \\
0.5 \\
0.0\end{array}\right]$ & Not significant \\
\hline Multi-layer clouds (\%): & $\left.\begin{array}{r}100 \\
75 \\
50\end{array}\right]$ & Not significant \\
\hline $\mathrm{BC}$ at base ( $\left.\mathrm{ng} \mathrm{m}^{-3}\right)$ : & $\left.\begin{array}{r}100 \\
75 \\
50 \\
25 \\
0\end{array}\right]$ & $\left.\begin{array}{r}100 \\
75 \\
50 \\
25 \\
0\end{array}\right] 1$ \\
\hline $\begin{array}{l}\text { \% below CloudSat } \\
\text { detection limit }{ }^{\mathrm{a}} \text { : }\end{array}$ & $\left.\begin{array}{r}40 \\
30 \\
20 \\
10 \\
0\end{array}\right]$ & $\left.\begin{array}{r}40 \\
30 \\
20 \\
10 \\
0\end{array}\right] \square \square \square$ \\
\hline$\%$ Mixed phase ${ }^{a, b}$ : & $\left.\begin{array}{r}100 \\
90 \\
80 \\
70\end{array}\right]$ & $\left.\begin{array}{r}100 \\
90 \\
80 \\
70\end{array}\right] \square \square$ \\
\hline$\%$ Precipitatinga,b: & $\left.\begin{array}{r}20 \\
15 \\
10 \\
5 \\
0\end{array}\right]$ & Not significant \\
\hline$r_{\text {el }}(\mu m)^{a, b}:$ & $\left.\begin{array}{r}11 \\
10 \\
9\end{array}\right][$ & $\left.\begin{array}{r}11 \\
10 \\
9\end{array}\right]$ \\
\hline Reflectivity (dBZ) ${ }^{a, b}$ : & $\left.\begin{array}{l}-16 \\
-20 \\
-24 \\
-28\end{array}\right] H_{4}$ & $\left.\begin{array}{l}-16 \\
-20 \\
-24 \\
-28\end{array}\right] \top \amalg I$ \\
\hline
\end{tabular}

Figure 4. Following Table 2, median characteristics of all (grey) and aerosol-influenced (orange) ONLi clouds over sea ice and open ocean where significant differences from clean conditions (blue) are observed. Data are not shown for cases without significant differences between clean and non-clean clouds. Bars denote the interquartile range of the data. Green shading indicates that significant differences were only observed in non-shallow $(>1.1 \mathrm{~km})$ clouds. Where indicated, data were only available for ${ }^{\mathrm{a}}$ clouds with bases $>750 \mathrm{~m}$ a.s.1., or ${ }^{\mathrm{b}}$ for clouds with CloudSat reflectivities $>-29 \mathrm{dBZ}$.

lated with a significant reduction in radar reflectivity, generally associated with smaller particles on theoretical grounds (Fig. 5, Table 2). Correspondingly, there is also a significantly higher probability that clean background clouds detected by CALIPSO would also be detected by CloudSat than all clouds or aerosol-impacted clouds (Table 2, Fig. 4).

The $r_{\mathrm{el}}$ values are derived from radar reflectivity, and as such, aerosol-related decreases in reflectivity suggest smaller $r_{\mathrm{el}}$ values. This observation follows expectations based on the Twomey effect, whereby aerosol particles acting as $\mathrm{CCN}$ create more droplets with smaller sizes. This observation is also in line with previous studies in the Arctic that have observed smaller $r_{\mathrm{el}}$ values correlated with an increasing influence of aerosols (Coopman et al., 2016; Lubin and Vogelmann, 2006; Peng et al., 2002; Tietze et al., 2011; Zamora et al., 2016; Zhao and Garrett, 2015). Here, non-shallow clouds $>1.1 \mathrm{~km}$ were associated with a systematic decrease in the cloud droplet effective radius as expected aerosol influence rose, and the estimated mode $r_{\mathrm{el}}$ values were, respectively, 10.3, 10.1, and $9.8 \mu \mathrm{m}$ for the ONLi clean cloud, allcloud, and the aerosol-influenced cloud subsets. This reduction was similar in the MOONLiT subset, at 10.5, 10.3, and $10.0 \mu \mathrm{m}$, respectively (Table S3). Unfortunately, the differences in $r_{\mathrm{el}}$ values are available only for the thicker clouds that CloudSat was able to observe, and in some cases, data were available only for the middle sections of clouds, which are expected to have higher relative $r_{\mathrm{el}}$ values. Thus, the estimated mean $r_{\mathrm{el}}$ values presented here might be skewed higher than would be derived from a dataset that more fully sampled the cloud fields, and the differences compared to clean background cases could underestimate actual differences. The difference in estimated ONLi $r_{\mathrm{el}}$ is about half of a previously reported, regionally integrated value for all Arctic clouds. Using MODIS $r_{\mathrm{el}}$ estimates in thicker clouds (median COD 11) with temperatures between 0 and $2{ }^{\circ} \mathrm{C}$, Tietze et al. (2011) saw a $\sim 1 \mu \mathrm{m}$ difference between the very cleanest clouds and median clouds. Note that these regionally averaged net changes in $r_{\mathrm{el}}$ are much smaller than would be expected locally in very polluted clouds (e.g., Zamora et al., 2016). Also note that decreases in $r_{\mathrm{el}}$ values are not significant in shallow clouds (Table 2, Fig. 4). We hypothesize that shallow ONLi clouds may be subject to different meteorological forcing than non-shallow clouds $>1.1 \mathrm{~km}$, as discussed in Sect. 3.3, and that this forcing might overwhelm cloud sensitivity to aerosols.

There are differences between cloud thicknesses in clean background air and other air masses that suggest the potential for meteorological co-variability in the samples. Clean ONLi clouds are optically and geometrically thicker than the other cloud groups (Table 2, Fig. 4). Lower moisture associated with continental airflow that carries the aerosol might explain this difference (Lohmann and Feichter, 2005), if recent surface contact with warmer, mostly midlatitude regions did not enhance moisture. However, in two related remote sensing studies where Arctic clouds were tightly binned within related meteorological groups, COD differences still appeared, and thus the authors attributed these differences to aerosoldriven changes in the liquid water path (LWP) (Coopman et al., 2016; Tietze et al., 2011).

We also observed a small but significant increase in the portion of detected liquid-phase clouds within sea ice clouds above $1.1 \mathrm{~km}$ (Tables 2 and S1). The trend in phase was not significant in MOONLiT cases (Table S3), and as with $r_{\mathrm{el}}$, it was also not significant in shallow clouds (Table 2, Fig. 4). However, only a strong trend in MOONLiT cases would be significant due to the very small sample size, and differential 

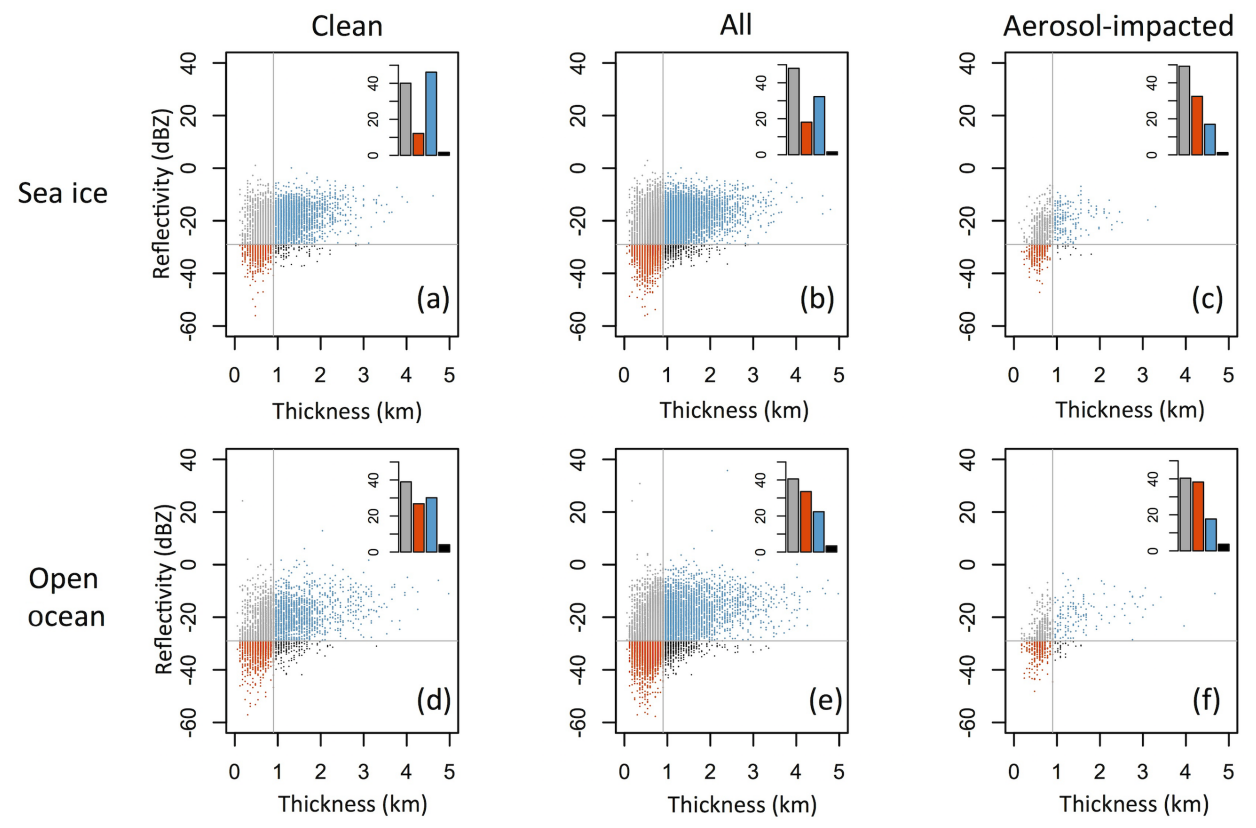

Figure 5. A comparison of CALIPSO ONLi cloud thickness (km) with CloudSat reflectivity (dBZ), as separated by sea ice and open-ocean regimes, and by clouds found in conditions labeled as clean background conditions, all conditions, and aerosol-impacted conditions. To better show changes in the two parameters, plots have been divided into four quadrants (above (grey and blue) and below (orange and black) the CloudSat reflectivity detection limit of $-29 \mathrm{dBZ}$ ), and above (blue and black) and below (orange and grey) a thickness of $0.9 \mathrm{~km}$. In the upper right of each plot is shown the percentage of cases within each quadrant, following the quadrant color scheme. Points represent clouds $>750 \mathrm{~m}$ a.s.1.

meteorological forcing on shallow clouds might overwhelm cloud sensitivity to aerosols at lower altitudes.

It is difficult to say whether the aerosol-related impacts on precipitation and radar reflectivity observed here are simply indicative of Twomey effects on liquid droplets, or whether some more complex mixed-phase and/or meteorological dynamics are also involved. One previous aircraft-based study offered some evidence to suggest that Twomey effects on droplet size may reduce the efficiency of secondary ice formation in the Arctic, particularly for thin clouds (Jackson et al., 2012), which would be consistent with the greater fraction of clouds estimated as liquid phase in non-background clouds. However, low sample number and surface and meteorological variability make this mechanism difficult to conclusively demonstrate on a larger scale. Laboratory studies indicate that smaller droplets may also lower the probability of critical ice embryo formation (Pruppacher and Klett, 2010).

The deactivation effect, whereby sulfates reduce icenucleating particle efficiency (Du et al., 2011; Girard et al., 2005, 2013; Lohmann, 2017), could also be consistent with our observations. Some limited in situ data support the occurrence of this mechanism (Jouan et al., 2012), but remote sensing data are contradictory (Grenier et al., 2009; Grenier and Blanchet, 2010), perhaps in part because of high uncertainties in below-cloud aerosols and a focus on ice-phase clouds, where it is more difficult for CALIPSO to accurately sepa- rate aerosols from ice particles. Other possible mechanisms that could explain the observed aerosol-related impacts on cloud properties are that polluted air might contain fewer INPs than clean background air (Borys, 1989) and/or that riming efficiency could be reduced (Lohmann and Feichter, 2005 ). If the very-low- $Z_{\mathrm{m}}$ ONLi clouds in our study do indeed contain fewer cases with ice particles as we suspect (see Sect. 3.3 above), the greater presence of very-low- $Z_{\mathrm{m}}$ clouds in aerosol-influenced conditions (Fig. 5) would support the possibility of these mechanisms dominating within the ONLi cloud subset. As more information is needed to verify phase in very-low- $Z_{\mathrm{m}}$ clouds, for now this possibility remains conjecture.

\subsection{Aerosol impacts on clouds over the open ocean}

Whereas cloud properties over sea ice were relatively tightly constrained, there was a much larger range in cloud properties over the open ocean (Table 2) that may in part reflect the greater variability in and higher magnitudes of surface turbulent heat and moisture fluxes over open ocean (e.g., Morrison et al., 2008; Strunin et al., 1997; Taylor et al., 2015). Variability reduced our ability to compare clouds within this regime, as did the uneven vertical distribution of aerosols. CALIPSOdetected aerosols in the Arctic are most frequently found at altitudes below $2 \mathrm{~km}$ (Devasthale et al., 2011b; Di Pierro et al., 2013; Kafle and Coulter, 2013; Winker et al., 2013). Over 
the open ocean, the median ONLi cloud base was above this level $(2.1 \mathrm{~km})$, and the median cloud base in the clean background cloud subset was even higher $(2.6 \mathrm{~km})$. The greater likelihood of clean background clouds being found at higher altitudes than non-background clouds likely induces a categorical bias in the cloud properties shown in Table 2 and Fig. 4.

To better understand any meteorological bias induced by aerosol height differences between clean vs. non-clean clouds, but still retain a sample size from our 2-year dataset that is as informative as possible, we separated clouds found over open ocean into three cloud-base-height bins (Table S2) and summarized the resulting information in Table 2 and Fig. 4. As over sea ice, the first bin includes clouds with base heights between 0.2 and $1.1 \mathrm{~km}$. This range encompasses the lower quartile range of all open-ocean clouds, isolating the shallow clouds that were observed to have different characteristics from the higher clouds in clean background conditions (Sect. 3.3). This range also happens to coincide with the lower quartile range of sea ice clouds so that these two bins are more or less comparable to each other with respect to cloud-base height. The second bin covers $1.2-3.2 \mathrm{~km}$ (the interquartile range of open-ocean clouds). The last bin includes clouds with bases $>3.2 \mathrm{~km}$. Although aerosol-influenced clouds still appear most often near the bases of their bins, the median cloud height and temperature differences within bins are fairly small (Table S2). Altituderelated biases from aerosol vertical distributions can be one cause for the loss of significant trends over the open ocean with altitude binning, indicated in Table 2 and by the green shading in Fig. 4. A loss of significance might also be caused by differences in cloud and aerosol responses with altitude, as is observed in shallow and non-shallow clouds over sea ice (Sect. 3.4); the general reduction in sampling when the data are stratified could also be a contributing factor.

There are some significant differences between clouds with and without aerosol influence in non-shallow ONLi clouds with bases above $1.1 \mathrm{~km}$. Similarly to clouds over sea ice, radar reflectivity is reduced with higher aerosol influence, and the fraction of low- $Z_{\mathrm{m}}$ clouds increases (Table 2, Fig. 4). Median $r_{\mathrm{el}}$ values dropped by $0.4 \mu \mathrm{m}$ in aerosolimpacted cases vs. clean background cases, compared to a $0.5 \mu \mathrm{m}$ reduction over sea ice. Clouds with bases $>1.1 \mathrm{~km}$, especially those at higher altitudes, are also thinner.

The reflectivity and $r_{\mathrm{el}}$ trends were not consistently observed in the MOONLiT subset, likely because smaller sample size caused the lack of statistical confidence in the binned samples (see Table S3). However, in a similar study using MODIS data for liquid clouds over the Arctic, Coopman et al. (2016) found significant trends in $r_{\mathrm{el}}$ with greater predicted aerosol concentrations when they stratified their results by lower-tropospheric stability (LTS), which is much greater over sea ice than over open ocean (Taylor et al., 2015). Like us, they found that the trends were weaker for regions with less expected LTS (which in our case would be over open ocean). The MOONLiT subset also had a significantly greater fraction of clouds that were assigned a liquid phase in aerosol-influenced samples compared to clean background samples for clouds where high-quality CloudSat phase information was available above $3.2 \mathrm{~km}$. This trend was not observed in the ONLi cloud subset, potentially because the differences between clean and aerosol-influenced cases were more ambiguous than in the MOONLiT cloud subset, but the trend toward more liquid clouds in aerosolinfluenced conditions was also observed in the higher ONLi cloud bin over sea ice. It is unclear whether a similar trend in phase would remain if more of the samples had contained high-quality phase data. Thus, we can only remark that the association between aerosols and liquid-phase clouds is not inconsistent with the deactivation effect or with reduced ice formation efficiency related to Twomey effects on droplet sizes.

In contrast to clouds found at higher levels, there were not many significant differences associated with aerosol influence in shallow ONLi clouds with bases below $1.1 \mathrm{~km}$. Moreover, some of the differences that were significant were small enough to not be very meaningful (e.g., a $20 \mathrm{~m}$ reduction in mean cloud-base height with a corresponding $0 \mathrm{~m}$ difference in median cloud-base height for clean clouds compared to all ONLi clouds). This observation suggests that dynamics might be overwhelming any aerosol changes to cloud microphysics in this regime, although our sample size for CloudSat-derived parameters was reduced by only assessing those clouds that were $>750 \mathrm{~m}$ above the surface to avoid ground clutter of the instrument. Median cloud-base heights in aerosol-influenced clouds were slightly higher $(120 \mathrm{~m})$ than clean clouds, which might have contributed to slightly colder cloud-top heights.

\subsection{Upper bounds on regional surface radiative impacts}

Over our 2-year time period, we identified tens of thousands of predominantly liquid ONLi clouds over the Arctic Ocean (Table 2). The sample size and regional spread of the data are large enough that we make the assumption that the cloud characteristics provided in Table 2 approximate the net nighttime cloud characteristics that exist for this cloud subset after exposure to the full spectrum of environmental conditions in each regime (sea ice and open ocean). We calculated the maximum regional radiative impact of clean background ONLi clouds on the nighttime surface, based on the regional frequency of occurrence of observable ONLi clouds in nighttime profiles over the entire (cloudy or clear) Arctic Ocean during our time period (2.52 and $4.84 \%$ over sea ice and open ocean, respectively; $3.23 \%$ over the full Arctic Ocean domain). Table 2 clean background cloud characteristics were used to calculate longwave flux changes to the surface compared to clear air, assuming cloud homogeneity and a single cloud layer, estimated at 56.05-58.44 $\mathrm{W} \mathrm{m}^{-2}$ 
and $20.86-21.48 \mathrm{~W} \mathrm{~m}^{-2}$ for sea ice and open-ocean regions, respectively. Maximum regional radiative impacts were estimated by multiplying these longwave fluxes by the ONLi cloud regional frequency of occurrence. Note that the presence of lower-level clouds will reduce the regional impact of ONLi clouds on the surface. Variable input parameters for the radiative impact calculations included cloud-base height, cloud thickness and COD, and $r_{\mathrm{el}}$ for clouds over sea ice and open ocean. Parameter values were taken from Table 2 median values, except for $r_{\mathrm{el}}$, where the interquartile range was used to reflect the larger uncertainty in that parameter.

The estimated maximum regional radiative impact of clean background ONLi clouds during polar night was between $1.41-1.47 \mathrm{~W} \mathrm{~m}^{-2}$ over sea ice and $1.01-1.04 \mathrm{~W} \mathrm{~m}^{-2}$ over open ocean. Maximum regional ONLi cloud impacts on the surface were smaller over the open ocean in part due to lower cloud temperatures associated with higher median cloud altitudes (an effect also seen during the SHEBA campaign; Shupe and Intrieri, 2004). This effect occurred despite there being more ONLi cloud cover over open ocean than over sea ice (a general trend that is also observed in total cloud fraction; Kay and L'Ecuyer, 2013). Also, the higher openocean clouds are expected to have lower liquid water paths (based on thinner CODs; Table 2), which influences longwave cloud forcing in very thin clouds that are not opaque in the infrared (Turner, 2007). For reference, using the CloudSat 2B-FLEXHR-lidar product, Kay and L'Ecuyer (2013) estimated the annual mean longwave forcing at the surface due to all clouds over sea ice and open ocean to be $\sim 24-36$ and $32-56 \mathrm{~W} \mathrm{~m}^{-2}$, respectively, depending on location. Barton et al. (2014) model-mean estimates for cloud impacts on surface longwave downwelling radiation during polar night over sea ice above $70^{\circ} \mathrm{N}$ (within the $95 \%$ confidence interval for surface temperatures) were $\sim 15-30 \mathrm{~W} \mathrm{~m}^{-2}$. These published estimates included the impacts of non-ONLi clouds, which the current study does not include.

We also estimated the maximum regional surface indirect radiative effect of aerosols on ONLi clouds over sea ice. To do so, we subtracted the maximum regional surface radiative impacts of the clean background cloud subset from the impacts expected of all observed ONLi clouds. Radiative calculations were not made for aerosol-driven effects on ONLi clouds over the open ocean due to the lack of significant differences in most relevant parameters and the altitude-based bias in the full open-ocean dataset. As with background clouds, aerosol indirect radiative effect estimates were made using the median cloud-base and cloud-top heights, the median COD, and the $r_{\mathrm{el}}$ interquartile range for sea ice clouds presented in Table 2. Based on this information, we estimate that excluding changes in cloud fraction, aerosols could have indirectly decreased present-day surface downwelling longwave fluxes during polar night over sea ice, from ONLi clouds specifically, by no more than $0.11 \mathrm{~W} \mathrm{~m}^{-2}$ ( $\sim 8 \%$ of the clean background effect), integrated over sea ice across the Arctic and for all aerosol concentrations. As with the background cloud estimates, this spatially integrated estimate assumes single-layer cloud conditions. Estimated regional aerosol indirect impacts specifically from the shallow (base height $<1.1 \mathrm{~km}$ ) sea ice ONLi clouds accounted for about half of this effect. In this instance, holding all other variables equal, aerosol-related changes in cloud optical depth were 1 order of magnitude more important for radiative effects than the changes in cloud droplet effective radius, and the changes in geometric thickness had nearly no impact on the longwave impacts. It is important to note that because this range is spatially integrated across the Arctic, local aerosol impacts in strong haze layers can be much higher (e.g., Garrett et al., 2004; Carrió et al., 2005; Zhao and Garrett, 2015). For example, Zhao and Garrett (2015) found that the local cloud indirect longwave forcing in single-layer stratus clouds at Barrow, Alaska, in the upper quartile of combustion aerosol concentrations was $8.1-9.9 \mathrm{~W} \mathrm{~m}^{-2}$ greater than in clouds associated with the lower quartile of combustion aerosol concentrations. In a similar study at Barrow, Lubin and Vogelmann (2006) used the lower and upper quartiles of aerosol particle concentrations to show that downwelling flux for high-condensation-nuclei $(\mathrm{CN})$ cases was $3.4 \mathrm{~W} \mathrm{~m}^{-2}$ higher than for low-CN cases.

To be clear, in estimating mean aerosol indirect effects in this section, we did not isolate absolute or local indirect aerosol effects from the confounding effects of meteorology and meteorological co-variability. Instead, we estimated the present-day impact of combustion-derived aerosols on the regional indirect effect that ultimately influences the presentday surface radiation (which includes any meteorological covariability present during these 2 years). This study was limited to only 2 years of data; future studies with more data might provide a better representation of the full range in aerosol and meteorological conditions the Arctic experiences over longer timescales.

As a final note, in this study we did not account for any aerosol-driven changes in cloud fraction. Aerosol-driven changes in cloud fraction may have occurred given the reduced precipitation in increasingly aerosol-impacted conditions over sea ice (Table 2, Fig. 4). If aerosols do increase cloud fraction, this effect could be the most important indirect impact that aerosols have on the Arctic's surface radiation budget because the presence of a cloud where there otherwise would not be one has more of a local impact on surface radiation than does a change to a cloud that is already present (Feingold et al., 2016; Sedlar and Devasthale, 2012; Shupe and Intrieri, 2004). Addressing these issues will require further study with additional types of data.

\section{Summary and conclusions}

Aerosol indirect effects have uncertain, but potentially large, impacts on the Arctic Ocean surface energy budget. As a step toward reducing uncertainty in present-day aerosol re- 
gional indirect effects on the surface, here we have better constrained the characteristics of a small subset of clean, average, and aerosol-impacted clouds for which we have relatively strong constraints on cloud properties and the associated aerosol environment. We focused on optically thin $(\mathrm{COD}<\sim 3$ ), predominantly liquid clouds collected at nighttime, which we termed ONLi clouds; they cover about $3 \%$ of the nighttime Arctic Ocean (5\% of total non-fog cloudy regions). However, within the ONLi cloud subset, it was possible to gain a high confidence in classification of clean background conditions with existing satellite remote sensing data. Using combined CALIPSO, CloudSat, and model output, we identify clean background clouds with a frequency that is much better than $64-67 \%$ of the time for top-layer clouds. Although the exact frequency of confident identification of clean background conditions beyond this range is difficult to quantify, particularly for clouds beneath another cloud layer, the level of confidence in clean background classification represents a substantial improvement compared to any previous remote sensing study of the Arctic region, to the best of our knowledge.

Within the ONLi cloud subset, we observed clear differences between clouds over open ocean and over sea ice, consistent with different surface and meteorological conditions in these two regimes. For example, when the surface is open ocean compared to sea ice, ONLi clouds are much more likely to overlay another cloud and to be present in the liquid phase. A greater frequency of multilayer clouds over the open ocean might affect the retreat of sea ice, and in turn, how this changes the impact of clouds on surface radiation of the Arctic Ocean. However, further study is needed to expand this observation beyond just conditions that contain ONLi clouds. There were also noticeable differences between shallow ONLi clouds (cloud bases $<1.1 \mathrm{~km}$ ) and higher ONLi clouds. As expected, shallow clouds were warmer and more likely be assigned a liquid- rather than mixed-phase CloudSat designation; they were also optically thicker and geometrically thinner. These differences in cloud properties may be in part due to the differing cloud formation mechanisms for shallow clouds. Previous studies support this hypothesis (e.g., Herman and Goody, 1976; Smith and Kao, 1995; Luo et al., 2008), as does the observation from the present study that shallow ONLi clouds are less sensitive to aerosols.

Except in shallow, open-ocean clouds, we observed that ONLi clouds are susceptible to aerosols. Consistent with other studies, the presence of aerosols exceeding background levels in clouds over sea ice is associated with reductions in $r_{\mathrm{el}}$, cloud geometric and optical thickness, precipitation, radar reflectivity, and COD. Perhaps due to greater boundarylayer turbulent fluxes, clouds over the open ocean appear to be less susceptible to the influence of aerosols, although some changes in phase and thickness were observed in the altitude-binned samples presented here. Due to aerosolinduced ONLi cloud changes over sea ice, we estimate that the region-wide maximum surface radiation impact during polar night is a $\sim 0.11 \mathrm{~W} \mathrm{~m}^{-2}$ cooling $(\sim 10 \%$ of the clean background cloud effect, excluding any impacts on cloud fraction, which were not assessed here), with shallow clouds contributing about half of this signal. It is unclear from the current work what the impact over open ocean might be. In comparison, the maximum region-wide direct radiative impact of clean ONLi clouds at night is estimated to be 1.0 and $1.4 \mathrm{~W} \mathrm{~m}^{-2}$ over sea ice and open-ocean regions, respectively. Note that the presence of multilayer clouds and cloud patchiness will reduce the radiative impact of ONLi clouds on the surface. Also, these maximum regional indirect effect estimates do not include any potential aerosol-driven changes in cloud extent, which could be important for estimating ONLi cloud overall regional indirect effects. Thus, aerosol-driven changes in cloud fraction dominate the uncertainty in estimates of the overall indirect aerosol radiative impact on the nighttime Arctic surface energy balance, based on this method. Unfortunately, the cloud fraction over the Arctic Ocean is particularly difficult to constrain over short timescales with passive remote sensing, given the low contrast between clouds and sea ice and long polar nighttime conditions, and due to very limited spatial coverage for active remote sensing.

We find no evidence to suggest that the glaciation indirect effect is important within the ONLi cloud subset. Beyond that, we have no strong support for aerosol impacts on mixed-phase cloud dynamics, although we see some evidence to suggest that large liquid particles need be present for ice formation in non-shallow ONLi clouds. These findings are in line with and expand upon previous aircraft observations (Jackson et al., 2012), although the deactivation effect could also explain the results. Aerosols were associated with higher fractions of liquid-phase clouds than in clean background cases in both sea ice ONLi clouds $>1.1 \mathrm{~km}$ and in open-ocean MOONLiT clouds $>3.2 \mathrm{~km}$ (for which additional cloud-selection criteria were applied; Table 1), for cases when high-quality phase data were available. Above $1.1 \mathrm{~km}$, open-ocean and sea ice clouds influenced by aerosol were less reflective at $94 \mathrm{GHz}$. Where high-quality CloudSat data were available, these clouds also had noticeably smaller estimated median $r_{\mathrm{el}}$ values, which is in line with previous studies. Over sea ice, aerosol-influenced clouds were less likely to be precipitating. Moreover, the fraction of low- $Z_{\mathrm{m}}$ clouds increases with aerosol presence in both regimes and at all altitudes except in shallow open-ocean clouds. These low$Z_{\mathrm{m}}$ clouds are more likely to be liquid-dominated, based on their lower radar reflectivity combined with their independently assigned, predominantly-liquid-phase designation by CALIPSO, their warmer median cloud temperatures, and in relation, their relative fraction that is $>2$ times higher over open ocean compared to sea ice. Together, these observations suggest that aerosols could play an important role in ice nucleation and nighttime radiative heating via possibly reduced ice formation efficiency related to Twomey effects on droplet sizes, or the deactivation effect on aerosol par- 
ticles. However, more information on cloud phase in lowreflectivity clouds is necessary to more fully explore these possibilities.

Although we limited this study to carefully describing average and clean background clouds within only a subset of remotely sensed Arctic Ocean clouds, we were able to provide the first observation-based estimate of regional-scale aerosol indirect effects on the surface for such clouds, demonstrating one way in which remote sensing observations can be used to quantitatively assess aerosol-cloud interactions on a regional scale in other conditions and at other locations as well. Given that so far only models have been able to estimate regional aerosol indirect effects on the surface energy balance, this study lays an important foundation for improving the quantification of aerosol indirect effects. The trade-off for selecting a small subset of clouds in this study is the low representativeness of ONLi clouds. To constrain observation-based aerosol impacts and nucleation processes on a larger scale for the Arctic Ocean, optically thick and ice-containing clouds must also be included. Expanding this study to a longer time period would help better incorporate the natural variability in Arctic meteorology and aerosols that might not be represented during this 2-year period. Including daylight or summertime air masses would also be useful; midsummer air masses tend to be cleaner than wintertime Arctic air masses and have a higher fraction of liquid-containing clouds (Van Tricht et al., 2016). Moreover, it would enable the use of MODIS data to examine cloud phase (e.g., via the DARDAR data product; Delanoë and Hogan, 2010) and droplet distribution.
Data availability. For access to the CALIPSO, ETOPO, NSIDC, and MERRA-2 data, see CALIPSO Science Team (2015a, b), Amante et al. (2009), Meier et al. (2009), and GMAO (2015), respectively. CloudSat data were obtained from http://www.cloudsat. cira.colostate.edu/order-data/. ARCTAS data were obtained from https://www-air.larc.nasa.gov/cgi-bin/ArcView/arctas. 


\section{Appendix A}

In Zamora et al. (2016), the case study CODs were not presented. Here, we calculated the relevant CODs from the following relationship:

$\mathrm{COD}=\frac{3}{2} \frac{\operatorname{LWC}\left(z_{\mathrm{t}}-z_{\mathrm{b}}\right)}{r_{\mathrm{el}}}$,

where LWC is the liquid water content, $z_{\mathrm{t}}$ and $z_{\mathrm{b}}$ are cloudtop and cloud-base height, respectively, and $r_{\mathrm{el}}$ is the cloud droplet effective radius. 


\section{The Supplement related to this article is available online at https://doi.org/10.5194/acp-17-7311-2017-supplement.}

Competing interests. The authors declare that they have no conflict of interest.

Acknowledgements. We recognize and thank the efforts and funding from the large number of people and agencies involved in making the following datasets available, including the NASA Langley Research Center Atmospheric Science Data Center, which provided the CALIPSO data; the CloudSat Data Processing Center run by the Cooperative Institute for Research in the Atmosphere (CIRA); and the NASA ARCTAS program and its members. Specifically we would like to thank Y. Kondo and B. Anderson for making their ARCTAS data publically available. We also thank G. de Boer, J. Creamean, G. Feingold, K.B. Huebert, J. Limbacher, S. Platnick, A. Solomon, H. Telg, M. Vaughan, D.L. Wu, Y. Yang, H. Yu, and T.L. Yuan for helpful discussions. The research of Lauren Zamora was supported by the NASA ACMAP program, via an appointment to the NASA Postdoctoral Program at the NASA Goddard Space Flight Center, administered by the Universities Space Research Association. The work of Ralph Kahn is supported in part by NASA's Climate and Radiation Research and Analysis Program under H. Maring and NASA's Atmospheric Composition Program under R. Eckman. The NILU team was supported by funding from NordForsk in the framework of eSTICC (eScience Tools for Investigating Climate Change at High Northern Latitudes).

Edited by: A. Perring

Reviewed by: two anonymous referees

\section{References}

Albrecht, B. A.: Aerosols, Cloud Microphysics, and Fractional Cloudiness, Science, 245, 1227-1230, https://doi.org/10.1126/science.245.4923.1227, 1989.

Amante, C. and Eakins, B. W.: ETOPO1 1 Arc-Minute Global Relief Model: Procedures, Data Sources and Analysis. NOAA Technical Memorandum NESDIS NGDC-24, National Geophysical Data Center, NOAA., https://doi.org/10.7289/V5C8276M, 2009.

Anderson, T. L. and Ogren, J. A.: Determining Aerosol Radiative Properties Using the TSI 3563 Integrating Nephelometer, Aerosol Sci. Technol., 29, 57-69, https://doi.org/10.1080/02786829808965551, 1998.

Austin, R. T. and Stephens, G. L.: Retrieval of stratus cloud microphysical parameters using millimeter-wave radar and visible optical depth in preparation for CloudSat: 1. Algorithm formulation, J. Geophys. Res.-Atmos., 106, 28233-28242, https://doi.org/10.1029/2000JD000293, 2001.

Barton, N. P., Klein, S. A., and Boyle, J. S.: On the Contribution of Longwave Radiation to Global Climate Model Biases in Arctic Lower Tropospheric Stability, J. Climate, 27, 7250-7269, https://doi.org/10.1175/JCLI-D-14-00126.1, 2014.
Bennartz, R., Shupe, M. D., Turner, D. D., Walden, V. P., Steffen, K., Cox, C. J., Kulie, M. S., Miller, N. B., and Pettersen, C.: July 2012 Greenland melt extent enhanced by low-level liquid clouds, Nature, 496, 83-86, https://doi.org/10.1038/nature12002, 2013.

Borys, R. D.: Studies of ice nucleation by Arctic aerosol on AGASP-II, J. Atmos. Chem., 9, 169-185, https://doi.org/10.1007/BF00052831, 1989.

Borys, R. D., Lowenthal, D. H., and Mitchell, D. L.: The relationships among cloud microphysics, chemistry, and precipitation rate in cold mountain clouds, Atmos. Environ., 34, 2593-2602, https://doi.org/10.1016/S1352-2310(99)00492-6, 2000.

Borys, R. D., Lowenthal, D. H., Cohn, S. A., and Brown, W. O. J.: Mountaintop and radar measurements of anthropogenic aerosol effects on snow growth and snowfall rate, Geophys. Res. Lett., 30, 1538, https://doi.org/10.1029/2002GL016855, 2003.

Boucher, O., Randall, D. A., Artaxo, P., Bretherton, C. S., Feingold, G., Forster, P. M., Kerminen, V.-M., Kondo, Y., Liao, H., Lohmann, U., Rasch, P., Satheesh, S. K., Sherwood, S., Stevens, B., and Zhang, X. Y.: Clouds and Aerosols, in Climate Change 2013: The Physical Science Basis. Contribution of Working Group I to the Fifth Assessment Report of the Intergovernmental Panel on Climate Change, edited by: Stocker, T. F., Qin, D., Plattner, G. K., Tignor, M., Allen, S. K., Boschung, J., Nauels, A., Xia, Y., Bex, V., and Midgley, P. M., Cambridge University Press, Cambridge, UK and New York, NY, USA., 2013.

Bradley, R. S., Keimig, F. T., and Diaz, H. F.: Climatology of surface-based inversions in the North American Arctic, J. Geophys. Res.-Atmos., 97, 15699-15712, https://doi.org/10.1029/92JD01451, 1992.

CALIPSO Science Team: CALIPSO/CALIOP Level 2, Lidar Aerosol Layer Data, version 3.01, Hampton, VA, USA: NASA Atmospheric Science Data Center (ASDC), https://doi.org/10.5067/CALIOP/CALIPSO/CAL_LID_L2_05kmALayProv-V3-01_L2-003.01 (last acess: 19 July, 2016), 2015a.

CALIPSO Science Team: CALIPSO/CALIOP Level 2, Lidar Cloud Layer Data, version 3.01, Hampton, VA, USA: NASA Atmospheric Science Data Center (ASDC), https://doi.org/10.5067/CALIOP/CALIPSO/CAL_LID_L2_05kmCLayProv-V3-01_L2-003.01 (last acess: 19 July, 2016), 2015b.

Carrió, G. G., Jiang, H., and Cotton, W. R.: Impact of Aerosol Intrusions on Arctic Boundary Layer Clouds. Part II: Sea Ice Melting Rates, J. Atmos. Sci., 62, 3094-3105, https://doi.org/10.1175/JAS3558.1, 2005.

Carslaw, K. S., Lee, L. A., Reddington, C. L., Pringle, K. J., Rap, A., Forster, P. M., Mann, G. W., Spracklen, D. V., Woodhouse, M. T., Regayre, L. A., and Pierce, J. R.: Large contribution of natural aerosols to uncertainty in indirect forcing, Nature, 503, 67-71, https://doi.org/10.1038/nature12674, 2013.

Cesana, G., Kay, J. E., Chepfer, H., English, J. M., and de Boer, G.: Ubiquitous low-level liquid-containing Arctic clouds: New observations and climate model constraints from CALIPSO-GOCCP, Geophys. Res. Lett., 39, L20804, https://doi.org/10.1029/2012GL053385, 2012.

Chakrabarty, R. K., Gyawali, M., Yatavelli, R. L. N., Pandey, A., Watts, A. C., Knue, J., Chen, L.-W. A., Pattison, R. R., Tsibart, A., Samburova, V., and Moosmüller, H.: Brown carbon aerosols from burning of boreal peatlands: microphysical properties, emission factors, and implications for di- 
rect radiative forcing, Atmos. Chem. Phys., 16, 3033-3040, https://doi.org/10.5194/acp-16-3033-2016, 2016.

Christensen, M. W., Stephens, G. L., and Lebsock, M. D.: Exposing biases in retrieved low cloud properties from CloudSat: A guide for evaluating observations and climate data, J. Geophys. Res.-Atmos., 118, 12120-12131, https://doi.org/10.1002/2013JD020224, 2013.

Coopman, Q., Garrett, T. J., Riedi, J., Eckhardt, S., and Stohl, A.: Effects of long-range aerosol transport on the microphysical properties of low-level liquid clouds in the Arctic, Atmos. Chem. Phys., 16, 4661-4674, https://doi.org/10.5194/acp16-4661-2016, 2016.

Curry, J. A., Schramm, J. L., Rossow, W. B., and Randall, D.: Overview of Arctic Cloud and Radiation Characteristics, J. Climate, 9, 1731-1764, https://doi.org/10.1175/15200442(1996)009<1731:OOACAR>2.0.CO;2, 1996.

Damoah, R., Spichtinger, N., Forster, C., James, P., Mattis, I., Wandinger, U., Beirle, S., Wagner, T., and Stohl, A.: Around the world in 17 days - hemispheric-scale transport of forest fire smoke from Russia in May 2003, Atmos. Chem. Phys., 4, 13111321, https://doi.org/10.5194/acp-4-1311-2004, 2004.

de Boer, G., Tripoli, G. J., and Eloranta, E. W.: Preliminary comparison of CloudSAT-derived microphysical quantities with ground-based measurements for mixed-phase cloud research in the Arctic, J. Geophys. Res.-Atmos., 113, D00A06, https://doi.org/10.1029/2008JD010029, 2008.

Delanoë, J. and Hogan, R. J.: Combined CloudSatCALIPSO-MODIS retrievals of the properties of ice clouds, J. Geophys. Res.-Atmos., 115, D00H29, https://doi.org/10.1029/2009JD012346, 2010.

Devasthale, A., Tjernström, M., and Omar, A. H.: The vertical distribution of thin features over the Arctic analysed from CALIPSO observations. Part II: Aerosols, Tellus B, 63, 86-95, https://doi.org/10.3402/tellusb.v63i1.16190, 2011b.

Di Pierro, M., Jaeglé, L., Eloranta, E. W., and Sharma, S.: Spatial and seasonal distribution of Arctic aerosols observed by the CALIOP satellite instrument (2006-2012), Atmos. Chem. Phys., 13, 7075-7095, https://doi.org/10.5194/acp-137075-2013, 2013.

Du, P., Girard, E., Bertram, A. K., and Shupe, M. D.: Modeling of the cloud and radiation processes observed during SHEBA, Atmos. Res., 101, 911-927, https://doi.org/10.1016/j.atmosres.2011.05.018, 2011.

Eckhardt, S., Quennehen, B., Olivié, D. J. L., Berntsen, T. K., Cherian, R., Christensen, J. H., Collins, W., Crepinsek, S., Daskalakis, N., Flanner, M., Herber, A., Heyes, C., Hodnebrog, Ø., Huang, L., Kanakidou, M., Klimont, Z., Langner, J., Law, K. S., Lund, M. T., Mahmood, R., Massling, A., Myriokefalitakis, S., Nielsen, I. E., Nøjgaard, J. K., Quaas, J., Quinn, P. K., Raut, J.-C., Rumbold, S. T., Schulz, M., Sharma, S., Skeie, R. B., Skov, H., Uttal, T., von Salzen, K., and Stohl, A.: Current model capabilities for simulating black carbon and sulfate concentrations in the Arctic atmosphere: a multi-model evaluation using a comprehensive measurement data set, Atmos. Chem. Phys., 15, 9413-9433, https://doi.org/10.5194/acp-15-9413-2015, 2015.

Fan, J., Wang, Y., Rosenfeld, D., and Liu, X.: Review of AerosolCloud Interactions: Mechanisms, Significance, and Challenges, J. Atmos, Sci., 73, 4221-4252, https://doi.org/10.1175/JAS-D16-0037.1, 2016.
Feingold, G., McComiskey, A., Yamaguchi, T., Johnson, J. S., Carslaw, K. S., and Schmidt, K. S.: New approaches to quantifying aerosol influence on the cloud radiative effect, P. Natl. Acad. Sci. USA, 113, 5812-5819, https://doi.org/10.1073/pnas.1514035112, 2016.

Forster, C., Wandinger, U., Wotawa, G., James, P., Mattis, I., Althausen, D., Simmonds, P., O’Doherty, S., Jennings, S. G., Kleefeld, C., Schneider, J., Trickl, T., Kreipl, S., Jäger, H., and Stohl, A.: Transport of boreal forest fire emissions from Canada to Europe, J. Geophys. Res.-Atmos., 106, 22887-22906, https://doi.org/10.1029/2001JD900115, 2001.

Frisch, S., Shupe, M., Djalalova, I., Feingold, G. and Poellot, M.: The Retrieval of Stratus Cloud Droplet Effective Radius with Cloud Radars, J. Atmos. Ocean. Tech., 19, 835-842, https://doi.org/10.1175/1520 0426(2002)019<0835:TROSCD>2.0.CO;2, 2002.

Fuelberg, H. E., Harrigan, D. L., and Sessions, W.: A meteorological overview of the ARCTAS 2008 mission, Atmos. Chem. Phys., 10, 817-842, https://doi.org/10.5194/acp-10-817-2010, 2010.

Ganeshan, M. and Wu, D. L.: An investigation of the Arctic inversion using COSMIC RO observations, J. Geophys. Res.-Atmos., 120, 2015JD023058, https://doi.org/10.1002/2015JD023058, 2015.

Garrett, T. J. and Zhao, C.: Increased Arctic cloud longwave emissivity associated with pollution from mid-latitudes, Nature, 440, 787-789, https://doi.org/10.1038/nature04636, 2006.

Garrett, T. J., Zhao, C., Dong, X., Mace, G. G., and Hobbs, P. V.: Effects of varying aerosol regimes on lowlevel Arctic stratus, Geophys. Res. Lett., 31, L17105, https://doi.org/10.1029/2004GL019928, 2004.

Gettelman, A.: Putting the clouds back in aerosol-cloud interactions, Atmos. Chem. Phys., 15, 12397-12411, https://doi.org/10.5194/acp-15-12397-2015, 2015.

Ghan, S., Wang, M., Zhang, S., Ferrachat, S., Gettelman, A., Griesfeller, J., Kipling, Z., Lohmann, U., Morrison, H., Neubauer, D., Partridge, D. G., Stier, P., Takemura, T., Wang, H., and Zhang, K.: Challenges in constraining anthropogenic aerosol effects on cloud radiative forcing using present-day spatiotemporal variability, P. Natl. Acad. Sci. USA, 113, 5804-5811, https://doi.org/10.1073/pnas.1514036113, 2016.

Ghan, S. J.: Technical Note: Estimating aerosol effects on cloud radiative forcing, Atmos. Chem. Phys., 13, 9971-9974, https://doi.org/10.5194/acp-13-9971-2013, 2013.

Girard, E., Blanchet, J.-P. and Dubois, Y.: Effects of arctic sulphuric acid aerosols on wintertime low-level atmospheric ice crystals, humidity and temperature at Alert, Nunavut, Atmos. Res., 73, 131-148, https://doi.org/10.1016/j.atmosres.2004.08.002, 2005.

Girard, E., Dueymes, G., Du, P., and Bertram, A. K.: Assessment of the effects of acid-coated ice nuclei on the Arctic cloud microstructure, atmospheric dehydration, radiation and temperature during winter, Int. J. Climatol., 33, 599-614, https://doi.org/10.1002/joc.3454, 2013.

GMAO: MERRA-2 tavgM_2d_rad_Nx: 2d,Monthly mean,TimeAveraged,Single-Level,Assimilation,Radiation Diagnostics V5.12.4, version 5.12.4, Greenbelt, MD, USA, Goddard Earth Sciences Data and Information Services Center (GES DISC), https://doi.org/10.5067/OU3HJDS973O0, 2015. 
Grenier, P. and Blanchet, J.-P.: Investigation of the sulphateinduced freezing inhibition effect from CloudSat and CALIPSO measurements, J. Geophys. Res.-Atmos., 115, D22205, https://doi.org/10.1029/2010JD013905, 2010.

Hamilton, D. S., Lee, L. A., Pringle, K. J., Reddington, C. L., Spracklen, D. V., and Carslaw, K. S.: Occurrence of pristine aerosol environments on a polluted planet, P. Natl. Acad. Sci. USA, 111, 18466-18471, https://doi.org/10.1073/pnas.1415440111, 2014.

Herman, G. and Goody, R.: Formation and Persistence of Summertime Arctic Stratus Clouds, J. Atmos. Sci., 33, 1537-1553, https://doi.org/10.1175/15200469(1976)033<1537:FAPOSA>2.0.CO;2, 1976.

Hobbs, P. V. and Rangno, A. L.: Ice Particle Concentrations in Clouds, J. Atmos. Sci., 42, 2523-2549, https://doi.org/10.1175/15200469(1985)042<2523:IPCIC>2.0.CO;2, 1985.

Huang, Y., Siems, S. T., Manton, M. J., Protat, A., and Delanoë, J.: A study on the low-altitude clouds over the Southern Ocean using the DARDAR-MASK, J. Geophys. Res.-Atmos., 117, D18204, https://doi.org/10.1029/2012JD017800, 2012.

Intrieri, J. M., Shupe, M. D., Uttal, T., and McCarty, B. J.: An annual cycle of Arctic cloud characteristics observed by radar and lidar at SHEBA, J. Geophys. Res.-Oceans, 107, SHE 5-1, https://doi.org/10.1029/2000JC000423, 2002.

Jackson, R. C., McFarquhar, G. M., Korolev, A. V., Earle, M. E., Liu, P. S. K., Lawson, R. P., Brooks, S., Wolde, M., Laskin, A., and Freer, M.: The dependence of ice microphysics on aerosol concentration in arctic mixed-phase stratus clouds during ISDAC and M-PACE, J. Geophys. Res., 117, D15207, https://doi.org/10.1029/2012JD017668, 2012.

Jacob, D. J., Crawford, J. H., Maring, H., Clarke, A. D., Dibb, J. E., Emmons, L. K., Ferrare, R. A., Hostetler, C. A., Russell, P. B., Singh, H. B., Thompson, A. M., Shaw, G. E., McCauley, E., Pederson, J. R., and Fisher, J. A.: The Arctic Research of the Composition of the Troposphere from Aircraft and Satellites (ARCTAS) mission: design, execution, and first results, Atmos. Chem. Phys., 10, 5191-5212, https://doi.org/10.5194/acp10-5191-2010, 2010.

Jaiser, R., Dethloff, K., Handorf, D., Rinke, A., and Cohen, J.: Impact of sea ice cover changes on the Northern Hemisphere atmospheric winter circulation, Tellus A, 64, 11595, https://doi.org/10.3402/tellusa.v64i0.11595, 2012.

Jiao, C. and Flanner, M. G.: Changing black carbon transport to the Arctic from present day to the end of 21st century, J. Geophys. Res.-Atmos., 121, 2015JD023964, https://doi.org/10.1002/2015JD023964, 2016.

Josey, S. A., Pascal, R. W., Taylor, P. K., and Yelland, M. J.: A new formula for determining the atmospheric longwave flux at the ocean surface at mid-high latitudes, J. Geophys. Res.-Oceans, 108, 3108, https://doi.org/10.1029/2002JC001418, 2003.

Jouan, C., Girard, E., Pelon, J., Gultepe, I., Delanoë, J., and Blanchet, J.-P.: Characterization of Arctic ice cloud properties observed during ISDAC, J. Geophys. Res.-Atmos., 117, D23207, https://doi.org/10.1029/2012JD017889, 2012.

Kacenelenbogen, M., Redemann, J., Vaughan, M. A., Omar, A. H., Russell, P. B., Burton, S., Rogers, R. R., Ferrare, R. A., and Hostetler, C. A.: An evaluation of CALIOP/CALIPSO's aerosol-above-cloud detection and retrieval capability over
North America, J. Geophys. Res.-Atmos., 119, 230-244, https://doi.org/10.1002/2013JD020178, 2014.

Kafle, D. N. and Coulter, R. L.: Micropulse lidar-derived aerosol optical depth climatology at ARM sites worldwide, J. Geophys. Res.-Atmos., 118, 7293-7308, https://doi.org/10.1002/jgrd.50536, 2013.

Kay, J. E. and L'Ecuyer, T.: Observational constraints on Arctic Ocean clouds and radiative fluxes during the early 21st century, J. Geophys. Res.-Atmos., 118, 7219-7236, https://doi.org/10.1002/jgrd.50489, 2013.

Kiehl, J. T., Schneider, T. L., Rasch, P. J., Barth, M. C., and Wong, J.: Radiative forcing due to sulfate aerosols from simulations with the National Center for Atmospheric Research Community Climate Model, Version 3, J. Geophys. Res.-Atmos., 105, 14411457, https://doi.org/10.1029/1999JD900495, 2000.

Kondo, Y., Matsui, H., Moteki, N., Sahu, L., Takegawa, N., Kajino, M., Zhao, Y., Cubison, M. J., Jimenez, J. L., Vay, S., Diskin, G. S., Anderson, B., Wisthaler, A., Mikoviny, T., Fuelberg, H. E., Blake, D. R., Huey, G., Weinheimer, A. J., Knapp, D. J., and Brune, W. H.: Emissions of black carbon, organic, and inorganic aerosols from biomass burning in North America and Asia in 2008, J. Geophys. Res.-Atmos., 116, D08204, https://doi.org/10.1029/2010JD015152, 2011.

Lance, S., Shupe, M. D., Feingold, G., Brock, C. A., Cozic, J., Holloway, J. S., Moore, R. H., Nenes, A., Schwarz, J. P., Spackman, J. R., Froyd, K. D., Murphy, D. M., Brioude, J., Cooper, O. R., Stohl, A., and Burkhart, J. F.: Cloud condensation nuclei as a modulator of ice processes in Arctic mixed-phase clouds, Atmos. Chem. Phys., 11, 8003-8015, https://doi.org/10.5194/acp11-8003-2011, 2011.

Lebo, Z. J., Johnson, N. C., and Harrington, J. Y.: Radiative influences on ice crystal and droplet growth within mixedphase stratus clouds, J. Geophys. Res.-Atmos., 113, D09203, https://doi.org/10.1029/2007JD009262, 2008.

Lee, S., Kahn, B. H., and Teixeira, J.: Characterization of cloud liquid water content distributions from CloudSat, J. Geophys. Res.Atmos., 115, D20203, https://doi.org/10.1029/2009JD013272, 2010.

Li, J., Huang, J., Stamnes, K., Wang, T., Lv, Q., and Jin, H.: A global survey of cloud overlap based on CALIPSO and CloudSat measurements, Atmos. Chem. Phys., 15, 519-536, https://doi.org/10.5194/acp-15-519-2015, 2015.

Liu, Z., Vaughan, M., Winker, D., Kittaka, C., Getzewich, B., Kuehn, R., Omar, A., Powell, K., Trepte, C., and Hostetler, C.: The CALIPSO Lidar Cloud and Aerosol Discrimination: Version 2 Algorithm and Initial Assessment of Performance, J. Atmos. Ocean. Tech., 26, 1198-1213, https://doi.org/10.1175/2009JTECHA1229.1, 2009.

Lohmann, U.: Anthropogenic Aerosol Influences on MixedPhase Clouds, Curr. Clim. Change Rep., 3, 32-44, https://doi.org/10.1007/s40641-017-0059-9, 2017.

Lohmann, U. and Feichter, J.: Global indirect aerosol effects: a review, Atmos. Chem. Phys., 5, 715-737, https://doi.org/10.5194/acp-5-715-2005, 2005.

Lohmann, U., Zhang, J., and Pi, J.: Sensitivity studies of the effect of increased aerosol concentrations and snow crystal shape on the snowfall rate in the Arctic, J. Geophys. Res.-Atmos., 108, 4341, https://doi.org/10.1029/2003JD003377, 2003. 
Lubin, D. and Vogelmann, A. M.: A climatologically significant aerosol longwave indirect effect in the Arctic, Nature, 439, 453456, https://doi.org/10.1038/nature04449, 2006.

Luo, Y., Xu, K.-M., Morrison, H., McFarquhar, G. M., Wang, Z., and Zhang, G.: Multi-layer arctic mixed-phase clouds simulated by a cloud-resolving model: Comparison with ARM observations and sensitivity experiments, J. Geophys. Res.-Atmos., 113, D12208, https://doi.org/10.1029/2007JD009563, 2008.

Mauritsen, T., Sedlar, J., Tjernström, M., Leck, C., Martin, M., Shupe, M., Sjogren, S., Sierau, B., Persson, P. O. G., Brooks, I. M., and Swietlicki, E.: An Arctic CCN-limited cloud-aerosol regime, Atmos. Chem. Phys., 11, 165-173, https://doi.org/10.5194/acp-11-165-2011, 2011.

McComiskey, A. and Feingold, G.: Quantifying error in the radiative forcing of the first aerosol indirect effect, Geophys. Res. Lett., 35, L02810, https://doi.org/10.1029/2007GL032667, 2008.

Meier, W., Fetterer, F., Savoie, M., Mallory, S., Duerr, R., and Stroeve, J. C.: NOAA/NSIDC Climate Data Record of Passive Microwave Sea Ice Concentration, Version 2. [G02202], NSIDC: National Snow and Ice Data Center, Boulder, Colorado, USA, https://doi.org/10.7265/N55M63M1, 2013.

Mioche, G., Jourdan, O., Ceccaldi, M., and Delanoë, J.: Variability of mixed-phase clouds in the Arctic with a focus on the Svalbard region: a study based on spaceborne active remote sensing, Atmos. Chem. Phys., 15, 2445-2461, https://doi.org/10.5194/acp15-2445-2015, 2015.

Morrison, H., Pinto, J. O., Curry, J. A., and McFarquhar, G. M.: Sensitivity of modeled arctic mixed-phase stratocumulus to cloud condensation and ice nuclei over regionally varying surface conditions, J. Geophys. Res.-Atmos., 113, D05203, https://doi.org/10.1029/2007JD008729, 2008.

Morrison, H., de Boer, G., Feingold, G., Harrington, J., Shupe, M. D., and Sulia, K.: Resilience of persistent Arctic mixed-phase clouds, Nat. Geosci., 5, 11-17, https://doi.org/10.1038/ngeo1332, 2012.

Ovchinnikov, M., Ackerman, A. S., Avramov, A., Cheng, A., Fan, J., Fridlind, A. M., Ghan, S., Harrington, J., Hoose, C., Korolev, A., McFarquhar, G. M., Morrison, H., Paukert, M., Savre, J., Shipway, B. J., Shupe, M. D., Solomon, A., and Sulia, K.: Intercomparison of large-eddy simulations of Arctic mixed-phase clouds: Importance of ice size distribution assumptions, J. Adv. Model. Earth Syst., 6, 223-248, https://doi.org/10.1002/2013MS000282, 2014.

Paris, J.-D., Stohl, A., Nédélec, P., Arshinov, M. Yu., Panchenko, M. V., Shmargunov, V. P., Law, K. S., Belan, B. D., and Ciais, P.: Wildfire smoke in the Siberian Arctic in summer: source characterization and plume evolution from airborne measurements, Atmos. Chem. Phys., 9, 9315-9327, https://doi.org/10.5194/acp9-9315-2009, 2009.

Peng, G., Meier, W. N., Scott, D. J., and Savoie, M. H.: A long-term and reproducible passive microwave sea ice concentration data record for climate studies and monitoring, Earth Syst. Sci. Data, 5, 311-318, https://doi.org/10.5194/essd-5-311-2013, 2013.

Peng, Y., Lohmann, U., Leaitch, R., Banic, C., and Couture, M.: The cloud albedo-cloud droplet effective radius relationship for clean and polluted clouds from RACE and FIRE.ACE, J. Geophys. Res.-Atmos., 107, AAC 1-1, https://doi.org/10.1029/2000JD000281, 2002.
Pruppacher, H. R. and Klett, P. J. D.: Heterogeneous Nucleation, in Microphysics of Clouds and Precipitation, Springer Netherlands, 287-360, 2010.

Rangno, A. L. and Hobbs, P. V.: Ice particles in stratiform clouds in the Arctic and possible mechanisms for the production of high ice concentrations, J. Geophys. Res.-Atmos., 106, 15065-15075, https://doi.org/10.1029/2000JD900286, 2001.

Ricchiazzi, P., Yang, S., Gautier, C. and Sowle, D.: SBDART: A Research and Teaching Software Tool for PlaneParallel Radiative Transfer in the Earth's Atmosphere, B. Am. Meteorol. Soc., 79, 2101-2114, https://doi.org/10.1175/15200477(1998)079<2101:SARATS>2.0.CO;2, 1998.

Rogers, R. R., Vaughan, M. A., Hostetler, C. A., Burton, S. P., Ferrare, R. A., Young, S. A., Hair, J. W., Obland, M. D., Harper, D. B., Cook, A. L., and Winker, D. M.: Looking through the haze: evaluating the CALIPSO level 2 aerosol optical depth using airborne high spectral resolution lidar data, Atmos. Meas. Tech., 7, 4317-4340, https://doi.org/10.5194/amt-7-4317-2014, 2014.

Sato, K., Inoue, J., Kodama, Y.-M., and Overland, J. E.: Impact of Arctic sea-ice retreat on the recent change in cloudbase height during autumn, Geophys. Res. Lett., 39, L10503, https://doi.org/10.1029/2012GL051850, 2012.

Sawamura, P., Moore, R. H., Burton, S. P., Chemyakin, E., Müller, D., Kolgotin, A., Ferrare, R. A., Hostetler, C. A., Ziemba, L. D., Beyersdorf, A. J., and Anderson, B. E.: HSRL2 aerosol optical measurements and microphysical retrievals vs. airborne in situ measurements during DISCOVER-AQ 2013: an intercomparison study, Atmos. Chem. Phys. Discuss., https://doi.org/10.5194/acp-2016-1164, in review, 2017.

Sedlar, J. and Devasthale, A.: Clear-sky thermodynamic and radiative anomalies over a sea ice sensitive region of the Arctic, J. Geophys. Res., 117, D19111, https://doi.org/10.1029/2012JD017754, 2012.

Serreze, M. C., Barrett, A. P., Stroeve, J. C., Kindig, D. N., and Holland, M. M.: The emergence of surface-based Arctic amplification, The Cryosphere, 3, 11-19, https://doi.org/10.5194/tc-311-2009, 2009.

Shaw, G. E.: The Arctic Haze Phenomenon, B. Am. Meteorol. Soc., 76, 2403-2413, https://doi.org/10.1175/1520 0477(1995)076<2403:TAHP>2.0.CO;2, 1995.

Sheridan, P. J., Andrews, E., Ogren, J. A., Tackett, J. L., and Winker, D. M.: Vertical profiles of aerosol optical properties over central Illinois and comparison with surface and satellite measurements, Atmos. Chem. Phys., 12, 11695-11721, https://doi.org/10.5194/acp-12-11695-2012, 2012.

Shupe, M. D. and Intrieri, J. M.: Cloud Radiative Forcing of the Arctic Surface: The Influence of Cloud Properties, Surface Albedo, and Solar Zenith Angle, J. Climate, 17, 616-628, https://doi.org/10.1175/15200442(2004)017<0616:CRFOTA>2.0.CO;2, 2004.

Shupe, M. D., Persson, P. O. G., Brooks, I. M., Tjernström, M., Sedlar, J., Mauritsen, T., Sjogren, S., and Leck, C.: Cloud and boundary layer interactions over the Arctic sea ice in late summer, Atmos. Chem. Phys., 13, 9379-9399, https://doi.org/10.5194/acp13-9379-2013, 2013.

Smith, W. S. and Kao, C.-Y. J.: Numerical Simulations of Observed Arctic Stratus Clouds Using a Second-Order Turbulence Closure Model, J. Appl. 
Meteorol., 35, 47-59, https://doi.org/10.1175/15200450(1996)035<0047:NSOOAS>2.0.CO;2, 1996.

Sodemann, H., Pommier, M., Arnold, S. R., Monks, S. A., Stebel, K., Burkhart, J. F., Hair, J. W., Diskin, G. S., Clerbaux, C., Coheur, P.-F., Hurtmans, D., Schlager, H., Blechschmidt, A.M., Kristjánsson, J. E., and Stohl, A.: Episodes of crosspolar transport in the Arctic troposphere during July 2008 as seen from models, satellite, and aircraft observations, Atmos. Chem. Phys., 11, 3631-3651, https://doi.org/10.5194/acp-113631-2011, 2011.

Stohl, A., Hittenberger, M., and Wotawa, G.: Validation of the lagrangian particle dispersion model FLEXPART against largescale tracer experiment data, Atmos. Environ., 32, 4245-4264, https://doi.org/10.1016/S1352-2310(98)00184-8, 1998.

Stohl, A., Eckhardt, S., Forster, C., James, P., and Spichtinger, N.: On the pathways and timescales of intercontinental air pollution transport, J. Geophys. Res.-Atmos., 107, 4684, https://doi.org/10.1029/2001JD001396, 2002.

Stohl, A., Forster, C., Eckhardt, S., Spichtinger, N., Huntrieser, H., Heland, J., Schlager, H., Wilhelm, S., Arnold, F., and Cooper, O.: A backward modeling study of intercontinental pollution transport using aircraft measurements, J. Geophys. Res.-Atmos., 108, 4370, https://doi.org/10.1029/2002JD002862, 2003.

Stohl, A., Forster, C., Frank, A., Seibert, P., and Wotawa, G.: Technical note: The Lagrangian particle dispersion model FLEXPART version 6.2, Atmos. Chem. Phys., 5, 2461-2474, https://doi.org/10.5194/acp-5-2461-2005, 2005.

Stohl, A., Aamaas, B., Amann, M., Baker, L. H., Bellouin, N., Berntsen, T. K., Boucher, O., Cherian, R., Collins, W., Daskalakis, N., Dusinska, M., Eckhardt, S., Fuglestvedt, J. S., Harju, M., Heyes, C., Hodnebrog, Ø., Hao, J., Im, U., Kanakidou, M., Klimont, Z., Kupiainen, K., Law, K. S., Lund, M. T., Maas, R., MacIntosh, C. R., Myhre, G., Myriokefalitakis, S., Olivié, D., Quaas, J., Quennehen, B., Raut, J.-C., Rumbold, S. T., Samset, B. H., Schulz, M., Seland, Ø., Shine, K. P., Skeie, R. B., Wang, S., Yttri, K. E., and Zhu, T.: Evaluating the climate and air quality impacts of short-lived pollutants, Atmos. Chem. Phys., 15, 10529-10566, https://doi.org/10.5194/acp-15-105292015, 2015.

Strunin, M. A., Postnov, A. A., and Mezrin, M. Y.: Arctic HazeMeteorological potential for contamination of arctic troposphere: Boundary layer structure and turbulent diffusion characteristics, Atmos. Res., 44, 37-51, https://doi.org/10.1016/S01698095(97)00008-2, 1997.

Taylor, P. C., Kato, S., Xu, K.-M., and Cai, M.: Covariance between Arctic sea ice and clouds within atmospheric state regimes at the satellite footprint level, J. Geophys. Res.-Atmos., 120, 2015JD023520, https://doi.org/10.1002/2015JD023520, 2015.

Tietze, K., Riedi, J., Stohl, A., and Garrett, T. J.: Space-based evaluation of interactions between aerosols and low-level Arctic clouds during the Spring and Summer of 2008, Atmos. Chem. Phys., 11, 3359-3373, https://doi.org/10.5194/acp-113359-2011, 2011.

Turner, D. D.: Improved ground-based liquid water path retrievals using a combined infrared and microwave approach, J. Geophys. Res.-Atmos., 112, D15204, https://doi.org/10.1029/2007JD008530, 2007.
Van Tricht, K., Lhermitte, S., Lenaerts, J. T. M., Gorodetskaya, I. V., L'Ecuyer, T. S., Noël, B., van den Broeke, M. R., Turner, D. D., and van Lipzig, N. P. M.: Clouds enhance Greenland ice sheet meltwater runoff, Nat. Commun., 7, 10266, https://doi.org/10.1038/ncomms10266, 2016.

Vaughan, M. A., Powell, K. A., Winker, D. M., Hostetler, C. A., Kuehn, R. E., Hunt, W. H., Getzewich, B. J., Young, S. A., Liu, Z., and McGill, M. J.: Fully Automated Detection of Cloud and Aerosol Layers in the CALIPSO Lidar Measurements, J. Atmos. Ocean.-Tech., 26, 2034-2050, https://doi.org/10.1175/2009JTECHA1228.1, 2009.

Wang, Z.: B-CLDCLASS-LIDAR Interface Control Document, available at: http://cswww.cira.colostate.edu/icd_pdf.php?avid= 36\&pvids=12 (last access: 11 August 2016), 2013.

Wilcox, L. J., Highwood, E. J., Booth, B. B. B., and Carslaw, K. S.: Quantifying sources of inter-model diversity in the cloud albedo effect, Geophys. Res. Lett., 42, 2015GL063301, https://doi.org/10.1002/2015GL063301, 2015.

Winker, D. M., Vaughan, M. A., Omar, A., Hu, Y., Powell, K. A., Liu, Z., Hunt, W. H., and Young, S. A.: Overview of the CALIPSO Mission and CALIOP Data Processing Algorithms, J. Atmos. Ocean. Tech., 26, 2310-2323, https://doi.org/10.1175/2009JTECHA1281.1, 2009.

Winker, D. M., Tackett, J. L., Getzewich, B. J., Liu, Z., Vaughan, M. A., and Rogers, R. R.: The global 3-D distribution of tropospheric aerosols as characterized by CALIOP, Atmos. Chem. Phys., 13, 3345-3361, https://doi.org/10.5194/acp-133345-2013, 2013.

Young, G., Jones, H. M., Choularton, T. W., Crosier, J., Bower, K. N., Gallagher, M. W., Davies, R. S., Renfrew, I. A., Elvidge, A. D., Darbyshire, E., Marenco, F., Brown, P. R. A., Ricketts, H. M. A., Connolly, P. J., Lloyd, G., Williams, P. I., Allan, J. D., Taylor, J. W., Liu, D., and Flynn, M. J.: Observed microphysical changes in Arctic mixed-phase clouds when transitioning from sea ice to open ocean, Atmos. Chem. Phys., 16, 13945-13967, https://doi.org/10.5194/acp-16-13945-2016, 2016.

Zamora, L. M., Kahn, R. A., Cubison, M. J., Diskin, G. S., Jimenez, J. L., Kondo, Y., McFarquhar, G. M., Nenes, A., Thornhill, K. L., Wisthaler, A., Zelenyuk, A., and Ziemba, L. D.: Aircraftmeasured indirect cloud effects from biomass burning smoke in the Arctic and subarctic, Atmos. Chem. Phys., 16, 715-738, https://doi.org/10.5194/acp-16-715-2016, 2016.

Zhang, D., Wang, Z., and Liu, D.: A global view of midlevel liquidlayer topped stratiform cloud distribution and phase partition from CALIPSO and CloudSat measurements, J. Geophys. Res.Atmos., 115, D00H13, https://doi.org/10.1029/2009JD012143, 2010.

Zhang, Y., Seidel, D. J., Golaz, J.-C., Deser, C., and Tomas, R. A.: Climatological Characteristics of Arctic and Antarctic Surface-Based Inversions, J. Climate, 24), 5167-5186, https://doi.org/10.1175/2011JCLI4004.1, 2011.

Zhao, C. and Garrett, T. J.: Effects of Arctic haze on surface cloud radiative forcing, Geophys. Res. Lett., 42, 2014GL062015, https://doi.org/10.1002/2014GL062015, 2015. 